This item was submitted to Loughborough's Research Repository by the author.

Items in Figshare are protected by copyright, with all rights reserved, unless otherwise indicated.

\title{
Formation and modification of dispersions using Shirasu Porous Glass membranes
}

\section{PLEASE CITE THE PUBLISHED VERSION}

http://www.crcnetbase.com/isbn/9781466580442

\section{PUBLISHER}

CRC Press (c) Taylor \& Francis Group

VERSION

AM (Accepted Manuscript)

\section{PUBLISHER STATEMENT}

This work is made available according to the conditions of the Creative Commons Attribution-NonCommercialNoDerivatives 4.0 International (CC BY-NC-ND 4.0) licence. Full details of this licence are available at: https://creativecommons.org/licenses/by-nc-nd/4.0/

\section{LICENCE}

CC BY-NC-ND 4.0

\section{REPOSITORY RECORD}

Vladisavljevic, Goran T.. 2015. "Formation and Modification of Dispersions Using Shirasu Porous Glass Membranes". figshare. https://hdl.handle.net/2134/19505. 


\title{
Formation and modification of dispersions using Shirasu Porous Glass membrane
}

\author{
Goran T. Vladisavljević
}

${ }^{a}$ Chemical Engineering Department, Loughborough University, Loughborough, Leicestershire LE11 3TU, United Kingdom, Email: G.Vladisavljevic@lboro.ac.uk.

\section{ABSTRACT}

This chapter deals with the production, properties, and macrofluidic applications of Shirasu Porous Glass (SPG) membrane. The first section provides an overview of the membrane microfluidic processes used for production and modification of liquid-liquid and gas-liquid micro- and nano-dispersions, such as direct and premix membrane emulsification with and without phase inversion, membrane demulsification, membrane micromixing / direct precipitation and micro- and nano-bubbling. In the last section of this chapter, SPG membranes are compared with conventional homogenisers and microfluidic drop generators in terms of production rate, droplet size uniformity, and applied shear stresses. The second section deals with the fabrication of SPG membrane by spinodal decomposition in $\mathrm{Na}_{2} \mathrm{O}-$ $\mathrm{CaO}-\mathrm{Al}_{2} \mathrm{O}_{3}-\mathrm{B}_{2} \mathrm{O}_{3}-\mathrm{SiO}_{2}$ type glass and morphological, mechanical, and hydrodynamic properties of SPG membrane. This chapter also covers modification of surface charge, contact angle and porosity of SPG membrane using different physical and chemical methods, such as deposition of silica nanoparticles onto membrane surface, coating with silicon resin, filling the pores with solvent-responsive polymer chains and chemical modification with silane coupling agents. The fourth section is focused on the effects of physical properties of the dispersed and continuous phase, operating parameters and membrane properties on the droplet size in direct and premix SPG membrane emulsification. In addition, the most common classes of micro- and nano-particles fabricated using SPG membrane were reviewed and their fabrication routes were discussed. It was concluded that a broad variety of different chemical and physicochemical processes can be combined with SPG membrane emulsification to convert droplets into uniform particle. The last section briefly discusses the generation of micro- and nano-bubbles using SPG membrane.

Keywords: Membrane Emulsification, Shirasu Porous Glass Membrane, Nanoparticles, Polymeric microspheres, Microbubbles, Janus particles, Core-Shell Particles. 


\section{Formation and modification of dispersions using membranes}

Synthetic membranes are mainly used for separation purposes and to achieve a chemical or biochemical conversion. Membrane separation processes are characterised by the fact that a feed stream is divided into two product streams of different chemical composition: retentate and permeate (Figure 1a) (Mulder, 1996). A shear rate is applied at the retentate/membrane interface to limit concentration polarisation and accumulation of the rejected solids on the high pressure side of the membrane. In the last two decades, microfluidic applications of membranes (formation of droplets and bubbles, micromixing of miscible liquids, droplet breakup and coalescence, etc.) are gaining in popularity, as a result of rising global interest in microfluidic technologies. Membrane microfluidic processes can be classified into two groups: (i) formation of dispersions (gas-liquid, liquid-liquid, and solid-liquid) (Figure 1b), and (ii) treatment of dispersions (demulsification, homogenisation and phase inversion). In a membrane dispersion process (Figure $1 \mathrm{~b}$ ), phase I is injected through a microporous membrane into phase II for the purpose of: (i) mixing of two miscible fluids, usually two liquid phases; (ii) forming droplets or bubbles of phase I into phase II. Membrane treatment of dispersions (Figure 1c) involves passing dispersion through the membrane which results in the physicochemical and mechanical interactions between the dispersed phase entities (bubbles/droplets/particles) and the pore walls leading to the modification of the original particle size distribution.

\subsection{Membrane dispersion processes}

Membrane dispersion processes are direct membrane emulsification (DME) (Nakashima et al., 2000), membrane micro- and nano-bubbling (Kukizaki and Goto, 2007; Kukizaki and Goto, 2006), and membrane micromixing (Chen et al., 2004). A shear is applied at the membrane surface to improve mixing efficiency or facilitate the detachment of bubbles or droplets from the membrane surface. In DME, one liquid (a dispersed phase) is injected through a microporous membrane into another immiscible liquid (the continuous phase) (Nakashima et al., 1991) leading to the formation of droplets at the membrane/continuous phase interface (Figure 2a). Hydrophobic membranes are needed to produce water-in-oil (W/O) emulsions (Cheng et al., 2008; Jing et al., 2006), and hydrophilic membranes are required to prepare oilin-water $(\mathrm{O} / \mathrm{W})$ emulsions (Figure 2a). In membrane microbubbling, a pressurised gas is 
forced through a hydrophilic membrane into aqueous continuous phase, leading to the formation of microbubbles $\left(1 \mu \mathrm{m}<\mathrm{d}_{\text {bubble }}<1 \mathrm{~mm}\right)$ or nanobubbles $\left(\mathrm{d}_{\text {bubble }}<1 \mu \mathrm{m}\right)$, depending on the pore size of the membrane (Figure 2b). Micromixing is interpenetration of miscible solutions at the molecular level and it is a crucial step in any homogeneous reaction (Okhonin et al., 2011). In membrane micromixing, an organic solution containing water-miscible organic solvent or an aqueous solution penetrates through a hydrophilic membrane into another aqueous phase for the purpose of mixing two solvents rapidly with each other. Membrane micromixing can be combined with direct precipitation to produce inorganic (Chen et al., 2004) and organic (Laouini et al., 2011) nanoparticles. Precipitation of inorganic compounds requires dispersion of aqueous solution of water soluble salt $\mathrm{A}$ into an aqueous solution of water soluble salt B and nanoparticles are formed as a result of chemical reaction between the two salts: $\mathrm{A}+\mathrm{B} \rightarrow \mathrm{C}+\mathrm{D}$, where one of the products is sparingly soluble in water (Table 1). Precipitation of organic compounds requires dispersion of water-miscible organic solvent containing particle-forming organic compounds into an aqueous phase (antisolvent), and precipitation occurs as a result of the lower solubility of the organic solutes in the aqueous phase (Figure 2c). Particle-forming organic compounds in pharmaceutical nanodispersions are active principle ingredient (API) and excipients and typical organic phase compositions are listed in Table 2.

\subsection{Membrane treatment of dispersions}

Membrane processes used to modify particle size distribution of dispersions can be classified into four groups: (a) Simple premix membrane emulsification (PME) (Suzuki et al., 1996); (b) PME with phase inversion (Suzuki et al., 1996); (c) membrane demulsification (Kukizaki and Goto, 2008); and (d) homogenization of suspensions by extrusion through membrane (Olson et al., 1979). In PME (Figure 3a), a pre-emulsion is forced through a microporous membrane (Suzuki et al., 1996) or a packed bed of uniform particles (van der Zwan et al., 2008; Yasuda et al., 2010). As in DME, hydrophobic and hydrophilic membranes are needed to produce $\mathrm{W} / \mathrm{O}$ and $\mathrm{O} / \mathrm{W}$ emulsions, respectively. If the transmembrane pressure is lower than the capillary pressure in a pore, the membrane will reject the droplets, while allowing the continuous phase liquid to pass through, which will lead to the separation of the emulsion into droplet-free continuous phase and concentrated emulsion (Koltuniewicz et al., 1995; Park et al., 1998). 
When the dispersed phase of the feed emulsion wets the membrane wall, the rate of droplet coalescence in the membrane pores is faster than the rate of droplet breakup, which leads to inversion of phases in the emulsion (Figure $3 b$ ) or separation of the feed emulsion into two distinct phases (Figure 3c). In PME with phase inversion, an $\mathrm{O} / \mathrm{W}$ or W/O/W emulsion undergoes inversion into a W/O emulsion as a result of permeation through a hydrophobic membrane (Suzuki et al., 1999; Kawashima et al., 1991). Similarly, a W/O emulsion can be inverted into $\mathrm{O} / \mathrm{W}$ emulsion after permeation through a hydrophilic membrane. A successful phase inversion requires that feed emulsion contains a blend of surfactants with a low and high hydrophilic-lipophilic balance (HLB) number (Suzuki et al., 1999) or otherwise, the emulsion breaking is more likely to occur than the phase inversion.

\subsection{Comparison of membranes with other methods to generate and treat dispersions}

Generation of droplets/bubbles in microfluidic devices such as T junctions (Thorsen et al., 2001) and flow focusing devices (Anna et al., 2003) usually involves injection of one fluid through a single microchannel into a stream of another immiscible fluid (Vladisavljević et al., 2012). The droplets/bubbles generated in microfluidic devices are highly uniform in size, with a typical coefficient of variation in dripping regime of $3 \%$ or less, and the drop generation frequency can exceed $10,000 \mathrm{~Hz}$ (Yobas et al., 2006). However, the volume flow rate of the dispersed phase in microfluidic devices is very low, usually $0.01-10 \mathrm{ml} \mathrm{h}^{-1}$, because there is typically only one droplet generation unit. Membranes overcome this low throughput limitation by providing countless number of pores that serve as massively parallel drop generation units. Considering that membrane modules can easily be integrated into a system with large total membrane area, while the integration of microfluidic devices is often challenging due to significant pressure drop in microfluidic channels and difficulties of controlling the flow rates of individual streams in complicated channel networks, it is clear that membranes are more suitable for large throughput applications. An advantage of microfluidic channels over membranes is in their ability to produce droplets with a complex morphology and to manipulate individual droplets with high precision after production.

Compared to high shear rotor-stator devices, high-pressure valve homogenizers, ultrasonic and static mixers, membrane dispersion devices operate under mild shear stress conditions, allowing high yields of inner droplets in multiple emulsion production (Surh et al., 2007; Vladisavljević and Williams, 2008; Dragosavac et al., 2012). Conventional emulsification 
techniques are not suitable when dealing with shear sensitive ingredients, because they apply more energy than needed to disrupt droplets (Karbstein and Schubert, 1995). In DME, a shear rate on the membrane surface is in the range of $(1-50) \times 10^{3} \mathrm{~s}^{-1}$ but droplets can be produced even in the absence of shear (Kukizaki, 2009; Kukizaki and Goto, 2009; Kosvintsev et al., 2008). A shear rate in rotor-stator devices such as high-shear in-line mixers and colloid mills is $(1-2) \times 10^{5} \mathrm{~s}^{-1}$ and it is up to $10^{7} \mathrm{~s}^{-1}$ in microfluidizers ${ }^{\circledR}$. In PME, a pressure drop accross the membrane is typically 1-10 bar, while in high-pressure valve homogenizers it ranges from 50 to over 2000 bar. In addition, energy input in conventional dispersion devices is not spatially uniform. E.g., in rotor-stator devices, shear forces are high in close proximity to a rotor and low in "dead zones", leading to the production of polydispersed emulsions. On the other hand, in the majority of membrane dispersion processes, shear is uniformly distributed over the membrane surface.

Another advantage of membrane emulsification compared to conventional emulsification devices is that membrane systems allow integration of emulsification step and emulsion postprocessing to achieve simultaneous drop generation and separation, chemical/biochemical conversion or physicochemical transformation. The examples include integration of DME or PME with liquid-liquid extraction (Chen et al., 2004c, Xu et al., 2005), biphasic enzymatic transformation (Li and Sakaki, 2008; Mazzei et al., 2010), pervaporation (Chang and Hatton, 2012), and complex coacervation (Piacentini et al., submitted).

\section{SPG membrane}

Membranes used to produce and treat dispersions should have the following properties: (i) uniform pores with a broad range of available mean pore sizes to suit different applications; (ii) low hydrodynamic resistance; (iii) high mechanical strength and thermal and chemical resistance; (iv) membrane material should be suitable for surface modification (modification of contact angle, surface charge, permeability, etc); (v) membrane fabrication process should allow precise control over the pore size and pore geometry. Shirasu Porous Glass (SPG) meets the majority of the above-mentioned criteria, and it is by far the most widely used microporous membrane in membrane dispersion processes. Advantages of SPG membrane over microengineered are in typically higher porosity, more versatile surface chemistry that can be applied and broader range of pore sizes available. 


\subsection{Fabrication of SPG membrane}

SPG membrane is fabricated from $\mathrm{Na}_{2} \mathrm{O}-\mathrm{CaO}-\mathrm{Al}_{2} \mathrm{O}_{3}-\mathrm{B}_{2} \mathrm{O}_{3}-\mathrm{SiO}_{2}$ or $\mathrm{Na}_{2} \mathrm{O}-\mathrm{CaO}-\mathrm{MgO}-$ $\mathrm{Al}_{2} \mathrm{O}_{3}-\mathrm{B}_{2} \mathrm{O}_{3}-\mathrm{SiO}_{2}$ type mother glass through phase separation by spinodal decomposition (Nakashima and Kuroki, 1981; Nakashima and Shimizu, 1986; Kukizaki and Nakashima, 2004). The mother glass is prepared by mixing and melting raw materials (Shirasu, limestone, and boric acid) at about $1350{ }^{\circ} \mathrm{C}$. Typical mixing ratios of raw materials for SPG membrane are given in Table 3. Soda ash $\left(\mathrm{Na}_{2} \mathrm{CO}_{3}\right)$ and sometimes $\mathrm{MgO}$ and $\mathrm{ZrO}_{2}$ are added to molten glass to adjust the rate and temperature of phase separation and alkaline durability of the glass. Shirasu is a volcanic ash deposit from southern Kyushu, which contains $72-77$ wt\% $\mathrm{SiO}_{2}, 10-15 \mathrm{wt} \% \mathrm{Al}_{2} \mathrm{O}_{3}$, and small amounts of other inorganic oxides (Table 4). Molten mother glass is shaped into tubes or flat discs by blowing or casting and then heat treated at $650-750{ }^{\circ} \mathrm{C}$ for the period ranging from several hours to several tens of hours. The thermal treatment causes a homogeneous glass melt to separate into an acid-insoluble $\left(\mathrm{Al}_{2} \mathrm{O}_{3}-\mathrm{SiO}_{2}\right.$ rich) phase and acid-soluble $\left(\mathrm{CaO}-\mathrm{B}_{2} \mathrm{O}_{3}\right.$ rich) phase (Figure 4). The phase-separated glass is then immersed into a hydrochloric acid solution to dissolve $\mathrm{CaO}-\mathrm{B}_{2} \mathrm{O}_{3}$ rich phase, which results in the formation of porous skeleton, whose composition is shown in Table 4. The porosity of SPG membrane is determined by the volume fraction of the acid-soluble phase in the phase separated mother glass and ranges between 50 and $60 \%$ (Vladisavljević et al., 2005). If the fraction of acid-soluble phase is too low or too high, separation may take place by the nucleation and growth mechanism. The nucleation and growth mechanism occurs in the metastable region of the phase diagram, between the spinodal and binodal lines (Figure 5), and leads to the formation of discrete spherical particles of one phase embedded in a continuous matrix of the other. This morphology is undesirable in the fabrication of SPG membrane and must be avoided.

Figure 5 depicts spinodal decomposition induced by cooling a homogeneous glass melt from a temperature $T_{1}$ at which all components are miscible in all proportions to a temperature $T_{2}$, which lies within the spinodal (unstable) region. A homogeneous glass with composition of $\mathrm{x}_{1}$ is separated into two immiscible phases with compositions of $x_{s}$ and $x_{i}$. The ratio of acidsoluble to acid-insoluble phase can be found by the lever rule and is equal to $\left(\mathrm{x}_{\mathrm{i}}-\mathrm{x}_{1}\right) /\left(\mathrm{x}_{1}-\mathrm{x}_{\mathrm{s}}\right)$. The mean pore diameter $d_{p}$ of SPG membrane can be controlled by adjusting the time, $t$ and temperature, $T_{2}$ of the heat treatment process (Kukizaki, 2010): 


$$
d_{p}=4 K^{1 / 2}\left(V_{p} / m_{m}\right) t^{1 / 2} \exp \left[-E_{a} /\left(2 R T_{2}\right)\right]
$$

where $K$ is a constant depending on the composition of mother glass, $E_{a}$ is the activation energy for diffusion during phase separation (400-600 $\mathrm{kJ} \mathrm{mol}^{-1}$ according to Nakashima (2002) and Kukizaki (2010)), $\mathrm{R}$ is the universal gas constant, and $\mathrm{V}_{\mathrm{p}} / \mathrm{m}_{\mathrm{m}}$ is the total pore volume per unit mass of dry membrane. Therefore, the mean pore diameter of SPG membrane is proportional to the square root of the heating time at any constant temperature, whereas a logarithm of the mean pore diameter is inversely proportional to $1 / T_{2}$ at constant heating time.

\subsection{Properties of SPG membrane}

SPG membrane is available from SPG Technology Ltd (Sadowara, Japan) over a wide spectrum of mean pore sizes ranging from 0.040 to $20 \mu \mathrm{m}$ (Table 5). The membrane has a uniform internal microstructure, as confirmed by X-ray microtomography (Vladisavljević et al., 2007), characterised by interconnected and tortuous cylindrical pores with a tortuosity factor of $\xi \approx 1.3$. On SEM and XMT images, the pores have a non-cylindrical shape (Figure 6 ), because they extend in all directions and include pore junctions. The number of pores per unit cross-sectional area of SPG membrane is given by (Vladisavljević et al., 2005):

$$
N / A_{m}=0.56 / d_{p}^{2}
$$

where $N / A_{m}$ and $d_{p}$ are in $\mathrm{m}^{-2}$ and $\mathrm{m}$, respectively. The hydraulic resistance of isotropic SPG membrane is given by (Vladisavljević et al., 2005):

$$
R_{m, s y m}=32 \xi^{2} \delta_{m} /\left(d_{p}^{2} \varepsilon\right)
$$

where $\delta_{m}$ is the membrane thickness and $\varepsilon$ is the membrane porosity. The hydraulic resistance of isotropic SPG membrane is relatively high (Table 5), due to its substantial thickness of $400-1000 \mu \mathrm{m}$, but can be reduced if the membrane is fabricated with anisotropic structure (Kukizaki and Goto, 2007b). Assuming that the pore tortuosity and porosity, $\xi$ and $\varepsilon$, are independent on the pore size, the hydraulic resistance of anisotropic SPG membrane is given by (Kukizaki and Goto, 2007b):

$$
R_{m, a s y m}=32 \xi^{2} \delta_{s k i n} /\left(d_{p, s k i n}^{2} \varepsilon\right)+32 \xi^{2} \delta_{\text {sup }} /\left(d_{p, s u p}^{2} \varepsilon\right)
$$

where $\delta_{\text {skin }}$ and $\delta_{\text {sup }}$ are the thicknesses of the skin and support layer, respectively and $d_{p, s k i n}$ are $d_{p, \text { sup }}$ their mean pore diameters. According to Kukizaki and Goto (2007b), the thickness of the skin layer is $6 \%$ of the overall membrane thickness and the ratio of the pore diameters in the skin and support layer is around 7, so it can be written: 


$$
R_{m, a s y m}=32\left(\xi^{2} / \varepsilon\right)\left(\delta_{\text {skin }} / d_{p, \text { skin }}^{2}+\delta_{\text {sup }} / d_{p, \text { sup }}^{2}\right)=R_{m, \text { sym }}\left(0.06 / 1+0.94 / 7^{2}\right) \approx 0.08 R_{m, \text { sym }}
$$

Therefore, the hydraulic resistance of asymmetric SPG membrane is just $8 \%$ of the $R_{m}$ value for symmetric membrane.

SPG is more stable in water and alkaline solutions than Porous Vycor ${ }^{\circledR}$ Glass, because it contains less $\mathrm{SiO}_{2}$ and more $\mathrm{Al}_{2} \mathrm{O}_{3}$ (Table 4). However, the durability of both membranes at high $\mathrm{pH}$ is poor, due to the attack of hydroxide ions on siloxane ( $\mathrm{Si}-\mathrm{O}-\mathrm{Si}$ ) bonds:

$\equiv \mathrm{Si}-\mathrm{O}-\mathrm{Si} \equiv+\mathrm{OH}^{-} \rightarrow \equiv \mathrm{Si}-\mathrm{O}^{-}+\equiv \mathrm{Si}-\mathrm{OH}$

Alkaline durability of SPG can be improved by incorporating about $3 \mathrm{~mol} \% \mathrm{ZrO}_{2}$ into the glass skeleton, which results in to the formation of stable $\mathrm{Zr}-\mathrm{O}-\mathrm{Si}$ bonds in the silicate network (Kukizaki, 2010). A compressive strength of SPG of 200-280 MPa is much higher than that of porous alumina or zirconia of the same porosity (Nakashima et al., 1992), because SPG is made up of a continuous glass skeleton with very few defects, while porous alumina or zirconia is composed of skeletal grains joined together discontinuously via grain boundaries.

\subsection{Surface modification of SPG membrane}

The surface of SPG membrane can be rendered hydrophobic by chemical modification with organosilane compounds such as chlorosilanes (Kukizaki and Wada, 2008) or coating with silicone resin (Vladisavljević et al., 2005). Monochlorosilanes such as trimethylchlorosilane (TMS) and octadecyldimethylchlorosilane (ODS) are the most suitable for hydrophobisation because they contain only one chlorine atom, which means that no polymerization between silane molecules can occur while they react with a silanol group on the pore surface (Figure 7a) (Kai et al., 2006). The longer the carbon chain length in the organosilane compound, more hydrophobic the membrane surface becomes (Kukizaki and Wada, 2008). The membrane hydrophobicity can be enhanced by depositing silica nanoparticles onto the surface of SPG membrane prior to treatment with TMS (Meng et al., 2013). The surface of SPG membrane can be made with thermoresponsive hydrophilic-hydrophobic properties by depositing silica nanoparticles containing poly(N-isopropylacrylamide) (PNIPAM) brushes grafted on their surface (Meng et al., 2010). The porosity and hydraulic resistance of SPG membrane can be modified over a wide range by incorporating dextran macromolecules within the pores (Kawakita et al., 2009; Seto et al., 2011). Dextran can be synthetized by in-situ enzymatic 
reaction between dextransucrase immobilised within the pores and sucrose from an aqueous solution that is passed through the membrane. A reversible change in the hydraulic resistance of the modified SPG membrane is a consequence of reversible extension and shrinkage of solvent-responsive dextran chains inside the pores.

The surface of untreated SPG surface has a negative zeta potential between -15 and $-45 \mathrm{mV}$ within a pH range of $2-8$, due to dissociation of silanol groups $\left(\equiv \mathrm{Si}-\mathrm{OH} \leftrightarrows \equiv \mathrm{SiO}^{-}+\mathrm{H}^{+}\right.$) (Kukizaki, 2009b). A positive charge on the membrane surface can be induced by treating the membrane with amino trialkoxysilanes, such as (3-aminopropyl)-trimethoxysilane (APTMS) and (3-aminopropyl)-triethoxysilane (APTES) (Figure 7b). Amino trialkoxysilanes undergo hydrolysis in aqueous solution resulting in the formation of silanol groups, which can be condensed with a silanol group on the SPG surface to form stable siloxane bond ( $\mathrm{Si}-\mathrm{O}-\mathrm{Si})$, required for surface modification.

\section{Emulsification using SPG membrane}

SPG membrane was widely used both in DME (Vladisavljević et al., 2004; Vladisavljević and Schubert, 2002) and PME (Vladisavljević et al., 2004b; 2006; 2006b). The advantages of PME over DME are in smaller droplet sizes (Figure 8) and higher transmembrane fluxes that can be achieved for any given pore size. On the other hand, a more severe membrane fouling and broader particle size distribution can be expected, compared to DME.

Various SPG membrane devices have been used in DME: (i) Cross flow module with tubular SPG membrane with an effective length of up to $500 \mathrm{~mm}$; (ii) A short SPG membrane tube with an effective length of 7-15 $\mathrm{mm}$ in a stirred vessel (internal or external pressure micro kit), and (iii) Rotating SPG membrane tube in a stagnant continuous phase. In the cross-flow DME system, a continuous phase liquid circulates from a storage tank through the bore of the membrane tube, and back to the tank (Figure 9). A dispersed phase-forming liquid stored in a pressure vessel is fed to the outside of the membrane tube and force to penetrate through the membrane under the pressure difference which is 1.1 to 5 times higher than the capillary pressure (Vladisavljević and Schubert, 2003a). The apparatus is operated continuously until a desired dispersed phase concentration is achieved in the emulsion. A transmembrane flux in cross-flow DME should be kept below $1-301 \mathrm{~m}^{-2} \mathrm{~h}^{-1}$ to obtain uniform droplets with a 
relative span factor of droplet size distribution of $0.25-0.45$. To increase transmembrane flux by two orders of magnitude, the continuous phase can be introduced into SPG membrane tube radially, as shown in Figure 10. A tangential introduction of the continuous phase generates spiral streamlines in the axial direction ("swirl flow") that exert a strong centrifugal force onto the inner surface of the membrane helping to sweep away droplets from the membrane surface (Shimoda et al., 2011). At the swirl-flow velocity of $0.85-5.4 \mathrm{~m} \mathrm{~s}^{-1}$ and the transmembrane flux of $0.3-3 \mathrm{~m}^{3} \mathrm{~m}^{-2} \mathrm{~h}^{-1}$, a relative span factor of droplet size distribution of 0.45-0.64 was achieved with an oil phase/water phase volume ratio in single-pass operation of up to 0.4 (Shimoda et al., 2011). Insertion of static turbulence promoters is an alternative method of increasing shear at the membrane surface in cross flow DME, while maintaining a low shear in the recirculation loop (Koris et al., 2011).

Cross-flow systems are easy to scale up and offer a constant shear stress along the membrane surface. However, at least several hundred millilitres of the continuous phase is required in the system to provide recirculation. SPG test kit shown in Figure 11a requires much smaller amount of continuous phase $(<50 \mathrm{ml})$ and can be operated with a very low hold-up volume of both phases, which is useful for expensive samples, such as medical preparations (Higashi and Setoguchi, 2000). The continuous phase is kept under agitation by a magnetic stir bar, while the dispersed phase is injected through the membrane tube from outside to inside. The membrane tube serves as a draft tube, which results in more effective circulation of the continuous phase than in an internal pressure SPG kit.

In addition to DME with static SPG membrane, where shear stress is controlled by fluid flow over the membrane surface, dynamic SPG membrane systems have been investigated, where shear is controlled by rotating the membrane within a static continuous phase (Pawlik and Norton, 2012; 2013). Rotating membrane systems can be operated batchwise or continuously. In a continuous flow operation, surface shear is decoupled from the cross flow velocity, which means that sufficient shear on the membrane surface can be achieved no matter how small the flow rate of the continuous phase may be. Therefore, emulsions with a high dispersed phase concentration can be produced without emulsion recycling, that can help to prevent damage to shear sensitive components and secondary breakup of the drops formed by the membrane.

SPG membrane rig used for PME is shown in Figure 11b. A pressurised pre-mix from a pressure vessel is passed through the membrane tube from outside to inside under the driving 
force of pressure difference ranging from several bars (for a $10-\mu \mathrm{m}$ membrane) to more than 10 bar (for $1-\mu \mathrm{m}$ membrane) and up to 50 bar for the membrane with sub-micron pore sizes. The product emulsion is collected inside the membrane tube and discharged from the bottom of the tube. In order to reduce the droplet size additionally and improve droplet size uniformity, product emulsion is passed repeatedly through the membrane (Vladisavljević et al., 2004b; 2006; 2006b). Membrane homogenisation using repeated cycles was first developed by Olson et al. (1979) and used for homogenisation of lipid vesicles using tracketch polycarbonate filters.

\subsection{Factors affecting droplet size in DME}

The size distribution of droplets produced in DME depends on a variety of factors, such as the pore size and wetting properties of the membrane, transmembrane flux, shear stress generated on the membrane surface, physical properties of the dispersed and continuous phase, a nature of the surfactant used and the surfactant concentration, emulsion formulation, etc (Joscelyne and Trägårdh, 2000).

\subsubsection{Influence of transmembrane pressure and flux}

The minimum transmembrane pressure for driving the oil phase through the pores is known as the capillary pressure, $P_{c a p}$, and is given by the Young-Laplace equation:

$$
P_{c a p}=\frac{4 \gamma_{w o} \cos \theta}{d_{p}}
$$

where $\gamma_{w o}$ is the equilibrium interfacial tension between the water and oil phase, $\theta$ is the contact angle, i.e. the angle formed by a water phase at the three phase boundary where the water phase, oil phase, and membrane intersect (Figure 12). A hydrophilic membrane $(\theta<$ $90^{\circ}$ ) is used in the production of $\mathrm{O} / \mathrm{W}$ emulsion, and thus $P_{c a p}>0$ and $P_{o}>P_{w}$. A hydrophobic membrane $\left(\theta>90^{\circ}\right)$ is used in the production of W/O emulsion, and thus $P_{c a p}<0$ and $P_{o}<$ $P_{w}$, i.e. the water phase pressure should be higher than the oil phase pressure by $P_{c a p}$ to drive the water phase through the membrane. Droplet generation regime is determined by capillary number given by: $C a=U_{d} \eta_{d} / \gamma_{w o}$, where $U_{d}$ is the velocity of the dispersed phase in a pore and $\mu_{d}$ is the viscosity of the dispersed phase. For low capillary numbers in the pores $(\mathrm{Ca}<\mathrm{Ca} r)$, droplets are formed in the dripping regime. In this regime, the interfacial tension force 
dominates the viscous force (Sugiura et al., 2002) and the droplet size is virtually independent on the transmembrane flux (Figure 13). For high capillary numbers $\left(\mathrm{Ca}>\mathrm{Ca} a_{c r}\right)$, droplets grow to large sizes $\left(d_{d}>10 d_{p}\right)$ before being detached from the membrane surface, which is termed as continuous outflow regime (Kobayashi et al., 2003). In this regime, the viscous force dominates the interfacial tension force and the droplet size sharply increases with increasing the dispersed phase velocity. The critical flux, $J_{c r}$, i.e. the transmembrane flux at which the transition from dripping to continuous outflow regime occurs is independent on the pore size and increases with decreasing the viscosity of the dispersed phase. Emulsions produced in the continuous outflow regime are highly polydisperse, due to the random nature of droplet formation process. In addition, flow transition from dripping to continuous outflow does not occur simultaneously for all pores, leading to the large variations in the droplet size for the pores operating in the dripping and continuous outflow regime.

\subsubsection{Influence of membrane pore size and shear stress on the membrane surface}

In dripping regime, a linear correlation between the mean droplet size and the mean pore size of SPG membrane exists: $d_{d}=K d_{p}$ (Figure 14), where $K$ typically ranges between 2.8 and 3.5 (Kukizaki and Goto, 2009; 2007c; Nakashima et al., 1991; Vladisavljević et al., 2006). A gradient of $d_{d}$ vs. $d_{p}$ line increases with decreasing the shear stress on the membrane surface, but even in the absence of any shear, $K$ is 3.3 for $\mathrm{O} / \mathrm{W}$ emulsions stabilised with $1 \%$ Tween 80 surfactant (Kukizaki and Goto, 2009). The mean droplet size is determined by a balance between the shear force exerted on the liquid-liquid interface by the continuous phase, $F_{d}$ and the capillary force, $F_{c a}$ (Kosvintsev et al., 2005):

$$
\begin{aligned}
& F_{c a}=\pi d_{p} \gamma \\
& F_{d}=9 \pi \sigma_{w} d_{d} \sqrt{\left(d_{d} / 2\right)^{2}-r_{p}^{2}}
\end{aligned}
$$

where $r_{p}$ is the pore radius and $\sigma_{w}$ is the shear stress on the membrane surface. The equation for the droplet diameter can be obtaining by solving Equations (6) and (7) for $d_{d}$ :

$$
d_{d}=\frac{\sqrt{18 \sigma_{w}^{2} r_{p}^{2}+2 \sqrt{81 \sigma_{w}^{4} r_{p}^{4}+4 r_{p}^{2} \sigma_{w}^{2} \gamma^{2}}}}{3 \sigma_{w}}
$$

Therefore, the mean drop diameter decreases with increasing shear stress on the membrane surface until it reaches a constant value at sufficiently high shear stresses (Figure 14). In 
cross-flow DME, $\sigma_{w}$ is a function of the mean velocity of the continuous phase inside the membrane tube, $U_{c}$ (Vladisavljević and Schubert, 2003b):

$\sigma_{w}=\lambda\left(\rho_{c} U_{c}^{2} / 8\right)$

where $\rho_{c}$ is the density of the continuous phase and $\lambda$ is the Moody friction factor. For laminar flow inside the membrane tube $(\operatorname{Re}<2300): \lambda=64 / R e$ and $\sigma_{w}=8 \eta_{c} U_{d} d_{m i}$, where $d_{m i}$ is the inner diameter of the membrane tube and $\eta_{c}$ is the viscosity of continuous phase. For the rotating SPG membrane, $\sigma_{w}$ can be estimated from (Vladisavljević and Williams, 2006): $\sigma_{w}=\frac{2 \eta_{c} r_{m o}^{2} \omega}{r_{b}^{2}-r_{m o}^{2}}$

where $\omega$ is the angular velocity of the membrane, $r_{m o}$ is the outer radius of the membrane tube and $r_{b}$ is the inner radius of the cylinder in which the membrane tube is rotating.

\subsubsection{Influence of surfactant}

The role of surfactant in ME is to rapidly adsorb to the newly formed oil-water interface to facilitate droplet detachment and stabilise the formed droplet against coalescence by reducing the interfacial tension. The effect of kinetics of adsorption of surfactant at oil-aqueous interface on the droplet size has been investigated by several groups (Schröder et al., 1998; Van der Graaf et al., 2004; Rayner et al., 2005). As a rule, the faster the surfactant molecules adsorb to the newly formed interface, the smaller the droplet size of the emulsion becomes. Surfactant molecules must not adsorb to the membrane surface, since otherwise the dispersed phase will spread over the membrane surface. This means that the functional groups of surfactant molecules must not carry a positive charge to avoid electrostatic deposition onto the negatively charged surface of SPG membrane (Nakashima et al., 1993). The use of cationic surfactants, e.g. alkyltrimethylammonium salts such as cetyltrimethyl-ammonium bromide (CTAB) leads to polydispersed O/W emulsions with $d_{d} / d_{p}>20$ (Nakashima et al., 1993). The use of zwitterionic surfactants must also be avoided, even when they carry a net negative charge. For example, lecithin at pH 3 fouls SPG membrane due to electrostatic interactions between positively charged groups $\left(-\mathrm{N}\left(\mathrm{CH}_{3}\right)_{3}{ }^{+}\right.$and $\left.-\mathrm{NH}_{3}{ }^{+}\right)$on phospholipid molecules and negatively charged silanol groups on SPG surface, although at pH 3 the net charge on lecithin molecules is negative (Surh et al., 2008). To produce cationic droplets using SPG membrane, the membrane must be treated with amino trialkoxysilanes to induce a 
positive charge on the surface (Figure $7 \mathrm{~b}$ ) or the charge of anionic droplets can be altered after ME by surfactant displacement (Vladisavljević and McClements, 2010).

\subsection{Factors affecting droplet size in PME}

The mean droplet size in PME depends on several parameters such as the mean pore size of SPG membrane, transmembrane pressure, number of passes through the membrane, viscosity of the continuous and dispersed phase and interfacial tension (Nazir et al., 2010). The mean droplet size is a non-linear function of the mean pore size of SPG membrane (Figure 15): $d_{d}=$ $K\left(d_{p}\right)^{n}$, where $n<1$. The $d_{d} / d_{p}$ ratio decreases with increasing the mean pore size and ranges from 1.5 to 1 at $d_{p}=5-20 \mu \mathrm{m}$ and the shear stress on the pore walls of $200 \mathrm{~Pa}$ (Vladisavljević et al., 2006). The critical pressure in PME is given by (Park et al., 2001):

$P_{\text {cap }}=\frac{\gamma\left[2+2 a^{6} / \sqrt{2 a^{6}-1} \times \arccos \left(1 / a^{3}\right)-4 a^{2}\right]}{a+\sqrt{a^{2}-1}}$

where $a=d_{1} / d_{p}$ and $d_{1}$ is the mean droplet size in pre-mix. If $d_{1} / d_{p} \gg 1$, the capillary pressure is given by Eq. (5). In PME, the transmembrane pressure resulting in the most uniform droplets is typically 10-50 times larger than $P_{c a p}$ (Vladisavljević et al., 2004b). The mean droplet size decreases with increasing the mean shear stress on the pore walls, given by:

$$
\sigma_{w, p}=8 \eta_{e} J \xi /\left(\varepsilon d_{p}\right)
$$

where $\eta_{e}$ is the viscosity of emulsion inside the pores. According to Eq. (12), the mean droplet size decreases with increasing transmembrane pressure, as shown in Figures 15 and 17b. The pressure energy is used for flow through the membrane pores and droplet disruption:

$$
\Delta p_{t m}=\underbrace{\eta_{e}\left(R_{m}+R_{f}\right) J}_{\Delta p_{\text {flow }}}+\underbrace{C \varphi\left(1 / d_{1}-1 / d_{p}\right) \gamma}_{\Delta p_{\text {disr }}}
$$

where $C$ is a constant, $\varphi$ is the volume fraction of the dispersed phase, $R_{m}$ is the membrane resistance, and $R_{f}$ is the fouling resistance. The second term in Equation (13) is based on the assumption that the energy needed for droplet disruption is proportional to the resultant increase in surface area. The fouling resistance occurs as a result of accumulation of the dispersed phase on the membrane surface (external fouling) and inside the pores (internal fouling). External fouling dominates at high $d_{d} / d_{p}$ ratios in the feed emulsion and low transmembrane pressures, whereas internal fouling dominates at high transmembrane pressures and small droplet sizes relative to the pore size. In repeated PME (Vladisavljević et al., 2004b): 


$$
\Delta p_{t m}=\underbrace{\eta_{e}\left(R_{m}+R_{f, i}\right) J_{i}}_{\Delta p_{\text {flow }}}+\underbrace{C \varphi\left(1 / d_{i}-1 / d_{i-1}\right) \gamma}_{\Delta p_{\text {disr }}}
$$

where $J_{i}$ and $R_{f, i}$ are $J$ and $R_{f}$ during ith pass through the membrane and $d_{i}$ and $d_{i-1}$ are the mean droplet diameter after ith and (i-1)th pass, respectively. The effect of varying droplet size on the viscosity of emulsion was disregarded in Equation (14). As the number of passes through the membrane increases at $\Delta p_{t m}=$ const, the mean droplet size tends to a constant minimum value, i.e. $d_{i} \rightarrow d_{i-1}$ (Figure $17 \mathrm{~b}$ ), which means that $\Delta p_{\text {disr }} \rightarrow 0$ and $\Delta p_{\text {flow }} \rightarrow \Delta p_{t m}$. Therefore, the term accounting for droplet disruption $\left(\Delta p_{\text {disr }}\right)$ becomes progressively less important than the flow term $\left(\Delta p_{\text {flow }}\right)$ and pressure energy of the feed mixture is increasingly used for providing emulsion flow through the membrane (Figure 16). As a consequence of redistribution of pressure terms in Eq. (14), the transmembrane flux at constant operating pressure increases after each pass through the membrane until a maximum flux is established. The maximum transmembrane flux in PME is limited by the membrane resistance, emulsion viscosity, and transmembrane pressure (Figure 17a).

The effect of continuous phase viscosity, dispersed phase concentration and transmembrane pressure on the mean droplet size and transmembrane flux in repeated PME is shown in Figure 17. The largest increase in flux between the two passes was observed between the first and second pass, because the most significant reduction in the mean droplet size was observed in the first pass. Under the same conditions, the limiting flux was substantially lower at the higher dispersed phase content, which was a consequence of both the higher viscosity of emulsion, $\eta_{e}$ and the higher $\Delta p_{\text {disr }}$ term in Eq. (14). Although the transmembrane fluxes were significantly higher at the lower viscosity of the continuous phase, the lowest droplet sizes were obtained at the higher viscosity of the continuous phase $(128 \mathrm{mPa} \cdot \mathrm{s})$, because of the higher shear stress acting on the pore walls; at $\Delta p_{t m}=150 \mathrm{kPa}$ and $\varphi_{o}=20 \mathrm{vol} \%$, the shear stress acting on the pore walls in the fifth pass was $\sigma_{w, p}=80 \mathrm{~Pa}$ at $\eta_{c}=1 \mathrm{mPa} \cdot \mathrm{s}$, whereas $\sigma_{w, p}$ was $1880 \mathrm{~Pa}$ at $\eta_{c}=126 \mathrm{mPa} \cdot \mathrm{s}$, in spite of the smaller transmembrane flux.

\subsection{Applications of direct and premix membrane emulsification using SPG membrane}

SPG membrane was initially used for the preparation of simple $\mathrm{O} / \mathrm{W}$ and $\mathrm{W} / \mathrm{O}$ emulsions with a narrow particle size distribution and adjustable mean particle size (Nakashima et al., 1991). Since the early 1990s, applications of SPG membrane emulsification technique have been 
extended to the production of multiple emulsions, such as solid-in-oil-in-water (S/O/W) (Kukizaki, 2009c), oil-in-water-in-oil (O/W/O) (Wei et al., 2013; Cho et al., 2005) and waterin-oil-in-water (W/O/W) (Surh et al., 2007), nano- and micro-emulsions (Koga et al., 2010; Oh et al., 2011; Laouini et al., 2012; Choi et al., 2012; Pradhan et al., 2013; Oh et al., 2013), emulsions with droplets laminated with multilayered biopolymer films (Vladisavljević and McClements, 2010; Gudipati et al., 2010; Nazir et al., 2012), microbubbles (Kukizaki and Goto, 2007), nanobubbles (Kukizaki and Goto, 2006), micro- and nano-particles (Vladisavljević and Williams, 2005; 2010), and vesicles (liposomes and niosomes) (Hwang et al., 2011; Pham et al., 2012).

Some examples of particles fabricated by DME or PME using SPG membrane are given in Table 6. Emulsion droplets were transformed into solid particles by implementing a variety of chemical reactions or physicochemical processes within the droplets, such as crosslinking of hydrogel forming polymers (Wei et al., 2013), polymerisation of monomer mixtures (Omi et al., 2005), solidification from a melt (Kukizaki and Goto, 2007c), polymer precipitation induced by solvent evaporation or extraction (Liu et al., 2005), redox reaction (Kakazu et al., 2010), complex coacervation (Kage et al., 1997), and thermal coagulation (El-Mahdy et al., 1998).

Crosslinking of gel-forming polymers within the droplets can be carried out using physical or chemical crosslinking methods (Wang et al., 2005). Physical crosslinking methods are helixcoil transition induced by cooling below the phase transition temperature (Zhou et al., 2007), thermal gelation induced by heating to about $37^{\circ} \mathrm{C}$ (Wu et al., 2008) and ionotropic gelation induced by the addition of multivalent ions (Liu et al., 2003). Melt solidification involves performing membrane emulsification above the melting point of the dispersed phase followed by emulsion cooling. This approach was used for fabrication of solid lipid particles for drug delivery applications (Kukizaki, 2009c), low-melting-point metal particles for soldering microcomponents in microelectronics (Torigoe et al., 2011) and thermochromic liquid crystal particles for heat transfer research (Segura et al., 2013).

Polymeric particles were produced by SPG membrane emulsification and subsequent suspension polymerisation (Omi et al., 1994) or solvent evaporation (Ito et al., 2011). Suspension polymerisation can be carried out in O/W (Ma et al., 2003), W/O (Hu et al., 2011) or W/O/W emulsion (Ma et al., 2004) and can be combined with droplet swelling technique 
(which is known as "two-stage" suspension polymerisation) to produce microspheres from hydrophilic monomers (Omi et al., 1997). Hollow particles were produced by combining SPG membrane emulsification with interfacial polymerisation (Chu et al., 2003), internal phase separation (Liu et al., 2010), molecular imprinting (Kou et al., 2012), and coating a shell around polymer particles by a sol-gel process (Kong et al., 2013) or interfacial crosslinking (Akamatsu et al., 2010) followed by core disintegration by chemical dissolution or calcination.

\section{Gas dispersion using SPG membrane}

Microbubbles or nanobubbles can be produced by injecting gas phase through a hydrophilic SPG membrane into an aqueous surfactant solution (direct injection method) or by loading porous particles fabricated by SPG membrane emulsification with a suitable gas (Hou et al., 2009). Monodispersed microbubbles with a relative span factor of about 0.5 were generated when the contact angle at membrane/water/air interface was in the range of $0^{\circ}<\theta<45^{\circ}$ and the bubble-to-pore size ratio was 7.9 (Kukizaki and Wada, 2008). Nanobubbles with a mean diameter of 360-720 $\mathrm{nm}$ and relative span factor of $0.45-0.48$ were produced by injecting air through SPG membranes with a mean pore diameter of 43-85 nm into 0.05-0.5 wt.\% sodium dodecyl sulfate (SDS) solution (Kukizaki and Goto, 2006). The mean size of nanobubbles was 8.6 times larger than the mean pore size and unaffected by the flow velocity of air in the pores within a range of $0.5-3.7 \mathrm{~m} \cdot \mathrm{s}^{-1}$ (Kukizaki and Goto, 2006). Microbubbles generated by SPG membranes can find applications in the production of aerated food products (Zúñiga and Aguilera, 2008), ultrasound contrast agents for ultrasonic examinations (Hou et al., 2009) and aerobic wastewater treatment (Liu et al., 2012; 2013), which can be combined with UV irradiation (Tasaki et al., 2009) or activated sludge process (Liu et al., 2012b).

\section{Conclusions}

SPG membranes are increasingly being used in microfluidic applications aiming at generating uniform micro- and nano-droplets, -bubbles, and -particles. They have also been used for modification of emulsions (phase inversion, demulsification and homogenization), as well as in micromixing/direct nanoprecipitation processes for production of inorganic and organic nanoparticles. SPG membranes can overcome low throughput limitations of conventional microfluidic junctions and flow focusing devices by providing countless number of pores that serve as massively parallel T junctions. Direct and premix membrane emulsification (DME 
and PME) are two main modes of operation of SPG membrane emulsification devices. In DME, the mean droplet size is proportional to the mean pore size and the proportionality constant is typically around 3, whereas in PME, the ratio of the mean droplet size to the mean pore size is less than 1.5 and can be below unity. To form uniformly sized particles, DME or PME can be combined with a variety of physichemical or chemical processes, that can be applied individually or in combination, such as polymerisation, cross-linking, solvent evaporation, electrostatic deposition, internal phase separation, coagulation, calcination, solgel chemistry, crystallisation, etc. 
Table 1. Formation of inorganic nanoparticles by membrane micromixing / direct precipitation method.

\begin{tabular}{lcccc}
\hline & Salt A & Salt B & $\begin{array}{c}\text { Membrane and } \\
\text { pore size }\end{array}$ & Reference \\
\hline $\begin{array}{l}\mathrm{BaSO}_{4} \\
\text { nanoparticles } \\
(\mathrm{d}=20-200 \mathrm{~nm})\end{array}$ & $0.1-0.3 \mathrm{M} \mathrm{BaCl}_{2}$ & $\begin{array}{c}0.1 \mathrm{M} \\
\mathrm{NaSO}_{4}\end{array}$ & $\begin{array}{c}5 \mu \mathrm{m} \text { stainless } \\
\text { steel, 0.2-0.9 } \mu \mathrm{m} \\
\mathrm{Ni}\end{array}$ & $\begin{array}{c}\text { Chen et al. } \\
(2004)\end{array}$ \\
$\begin{array}{l}\text { Anatase-TiO } \\
\text { nanoparticles } \\
(\mathrm{d}=9-20 \mathrm{~nm})\end{array}$ & $\begin{array}{c}0.03-0.15 \mathrm{M} \\
\mathrm{Ti}\left(\mathrm{SO}_{4}\right)_{2}\end{array}$ & $\begin{array}{c}0.1-0.3 \mathrm{M} \\
\mathrm{NH}_{4} \mathrm{HCO}_{3}\end{array}$ & $0.2 \mu \mathrm{m} \mathrm{Ni}$ & $\begin{array}{c}\text { Chen et al. } \\
(2004 \mathrm{~b})\end{array}$ \\
$\begin{array}{l}\mathrm{ZnO} \text { nanoparticles } \\
(\mathrm{d}=9.4-14 \mathrm{~nm})\end{array}$ & $0.2-1.2 \mathrm{M} \mathrm{ZnSO}_{4}$ & $\begin{array}{c}2.25 \mathrm{M} \\
\mathrm{NH}_{4} \mathrm{HCO}_{3}\end{array}$ & $\begin{array}{c}5 \mu \mathrm{m} \text { stainless } \\
\text { steel }\end{array}$ & $\begin{array}{c}\text { Wang et al. } \\
(2010)\end{array}$ \\
\hline
\end{tabular}

Table 2. Formation of organic nanoparticles by membrane micromixing / direct precipitation method.

\section{Excipients Solvent and API $\begin{gathered}\text { Membrane } \\ \text { and pore size }\end{gathered}$ Reference}

\begin{tabular}{|c|c|c|c|c|}
\hline $\begin{array}{l}\text { BDP-loaded } \\
\text { liposomes } \\
(\mathrm{d}=60-200 \mathrm{~nm})\end{array}$ & $\begin{array}{l}\text { 20-60mg ml } \\
\text { Lipoïd }^{\circledR} \mathrm{E} 80+ \\
\text { 4-12 } \mathrm{mg} \mathrm{ml}^{-1} \mathrm{Chl}\end{array}$ & $\begin{array}{c}\text { Ethanol + } \\
0.4 \mathrm{mg} / \mathrm{ml} \text { BDP }\end{array}$ & $\begin{array}{c}0.4-10.2 \mu \mathrm{m} \\
\text { SPG }\end{array}$ & $\begin{array}{c}\text { Jaafar- } \\
\text { Maalej et al. } \\
(2011)\end{array}$ \\
\hline $\begin{array}{l}\text { SPL-loaded } \\
\text { liposomes } \\
(\mathrm{d}=110-190 \mathrm{~nm})\end{array}$ & $\begin{array}{c}\text { 20-80mg/ml } \\
\text { Lipoïd }^{\circledR} \mathrm{E} 80+ \\
4-16 \mathrm{mg} \mathrm{ml}^{-1} \mathrm{Chl}\end{array}$ & $\begin{array}{c}\text { Ethanol + } 3 \mathrm{mg} \\
\mathrm{ml}^{-1} \mathrm{SPL}\end{array}$ & $\begin{array}{c}40 \mathrm{~nm} \text { PP } \\
\text { hollow fiber }\end{array}$ & $\begin{array}{l}\text { Laouini et } \\
\text { al. (2011) }\end{array}$ \\
\hline $\begin{array}{l}\text { Vitamin E-loaded } \\
\text { PCL } \\
\text { nanoparticles } \\
(\mathrm{d}=250-350 \mathrm{~nm})\end{array}$ & $5 \mathrm{mg} / \mathrm{ml} \mathrm{PCL}$ & $\begin{array}{l}\text { Acetone }+4 \mathrm{mg} \\
\mathrm{ml}^{-1} \text { vitamin } \mathrm{E}\end{array}$ & $\begin{array}{l}0.2-10.2 \mu \mathrm{m} \\
\text { SPG }\end{array}$ & $\begin{array}{l}\text { Khayata et } \\
\text { al. }(2012)\end{array}$ \\
\hline $\begin{array}{l}\text { caffeine and SPL- } \\
\text { loaded niosomes } \\
(\mathrm{d}=111-115 \mathrm{~nm})\end{array}$ & $\begin{array}{l}105 \mathrm{mM} \mathrm{Tw}+ \\
105 \mathrm{mM} \mathrm{Chl} \mathrm{+} \\
23.3 \mathrm{mM} \mathrm{DCP}\end{array}$ & $\begin{array}{l}\text { Ethanol }+10 \mathrm{mg} \\
\mathrm{ml}^{-1} \text { caffeine or } \\
3 \mathrm{mg} \mathrm{ml}^{-1} \mathrm{SPL}\end{array}$ & $0.9 \mu \mathrm{m} \mathrm{SPG}$ & $\begin{array}{l}\text { Pham et al. } \\
\text { (2012) }\end{array}$ \\
\hline
\end{tabular}

API - Active principle ingredient, BDP - beclomethasone dipropionate, $\mathrm{Chl}$ - cholesterol, DCP - dicetyl phosphate, Lipoïd ${ }^{\circledR}$ E80 - egg yolk lecithin from Lipoïd GmbH, PP polypropylene, PCL - polycaprolactone, SPL - spironolactone, Tw - Tween 60. 
Table 3. Typical mixing ratios of raw materials in the production of $\mathrm{SPG}$ from $\mathrm{Na}_{2} \mathrm{O}-\mathrm{CaO}-$ $\mathrm{Al}_{2} \mathrm{O}_{3}-\mathrm{B}_{2} \mathrm{O}_{3}-\mathrm{SiO}_{2}$ mother glass (Nakashima, 2002)*

\begin{tabular}{lc}
\hline & Wt\% \\
\hline Shirasu & 51 \\
Limestone & 23 \\
Boric acid & 22 \\
Soda ash & 4 \\
\hline
\end{tabular}

${ }^{*} \mathrm{MgO}(\approx 5 \mathrm{wt} \%)$ can also be added.

Table 4. Composition of primary glass ${ }^{*}, \mathrm{SPG}^{*}$, and porous Vycor glass and Pyrex glass (Nakashima et al., 1992; Nakashima, 2002).

\begin{tabular}{lcccc}
\hline & $\begin{array}{c}\text { Primary glass } \\
\text { for SPG, wt } \%\end{array}$ & $\begin{array}{c}\text { SPG } \\
\text { wt\% }\end{array}$ & $\begin{array}{c}\text { Vycor® glass } \\
\text { wt\% }\end{array}$ & $\begin{array}{c}\text { Pyrex® glass } \\
\text { wt\% }\end{array}$ \\
\hline $\mathrm{SiO}_{2}$ & 49 & 69 & $94-99.5$ & 81 \\
$\mathrm{Al}_{2} \mathrm{O}_{2}$ & 10 & 13 & $0-0.5$ & 2 \\
$\mathrm{CaO}$ & 17 & 2 & - & - \\
$\mathrm{B}_{2} \mathrm{O}_{3}$ & 16 & 7 & $0.2-6.0$ & 13 \\
$\mathrm{Na}_{2} \mathrm{O}$ & 5 & 5 & $<0.1$ & 4 \\
$\mathrm{~K}_{2} \mathrm{O}$ & 2 & 4 & - & - \\
$\mathrm{Fe}_{2} \mathrm{O}_{3}$ & 1 & 0.4 & - & - \\
\hline
\end{tabular}

* Based on proportions of raw materials given in Table 3. 
Table 5. Properties of commercial isotropic (symmetric) SPG membrane (Vladisavljević et al., 2005; Nakashima, 2002; Kukizaki, 2009b; Nakashima et al., 1992).

\section{Shape}

Thickness, $\delta_{\mathrm{m}}$

Compressive strength

Pore diameter, $\mathrm{d}_{\mathrm{p}}$

Porosity, $\varepsilon$

True density

Zeta potential at $\mathrm{pH}=3-10$ and $\mathrm{C}_{\mathrm{NaCl}}=1-100 \mathrm{~mol} \mathrm{~m}^{-3}$

Pore tortuosity, $\xi$

Number of pores per unit cross-sectional area, N/A $A_{m}$

Specific pore volume, $\mathrm{V}_{\mathrm{p}} / \mathrm{m}_{\mathrm{m}}$

Hydraulic resistance, $\mathrm{R}_{\mathrm{m}, \mathrm{sym}}$
Tubes or flat discs

$0.4-1 \mathrm{~mm}$

200-280 Mpa

$0.04-20 \mu \mathrm{m}$

$50-60 \%$

$2000-2500 \mathrm{~kg} \mathrm{~m}^{-3}$

$-15-(-45) \mathrm{mV}$

$1.25-1.4$

$10^{9}-10^{14} \mathrm{~m}^{-2}$

$0.5-0.6 \mathrm{dm}^{3} \mathrm{~kg}^{-1}$

$10^{8}-10^{12} \mathrm{~m}^{-1}$ 
Table 6. Examples of microparticles fabricated using DME and PME with SPG membrane.

\begin{tabular}{|c|c|c|c|}
\hline Product type & Example & $\begin{array}{l}\text { Secondary reaction/process } \\
\text { after DME or PME }\end{array}$ & Authors \\
\hline Ceramic particles & $\begin{array}{l}\text { Silica nano- or micro- } \\
\text { particles }\end{array}$ & $\begin{array}{l}\text { Polymerisation of silicic acids by } \\
\text { interfacial or internal reaction }\end{array}$ & Kandori et al. (1992) \\
\hline $\begin{array}{l}\text { Liquid crystal } \\
\text { particles }\end{array}$ & $\begin{array}{l}\text { Thermochromic liquid } \\
\text { crystal particles }\end{array}$ & $\begin{array}{l}\text { Melt crystallization in } \mathrm{O} / \mathrm{W} \\
\text { emulsion }\end{array}$ & Segura et al. (2013) \\
\hline Carbon particles & Carbon cryogel & $\begin{array}{l}\text { sol-gel polycondensation } \\
\text { followed by freeze-drying and } \\
\text { carbonization }\end{array}$ & $\begin{array}{l}\text { Yamamoto et al. } \\
(2010)\end{array}$ \\
\hline \multirow{2}{*}{ Metal particles } & $\begin{array}{l}\text { Solder metal } \\
\text { microparticles }\end{array}$ & $\begin{array}{l}\text { Solidification of liquid metal in } \\
\mathrm{M} / \mathrm{W} \text { or } \mathrm{M} / \mathrm{O} \text { emulsion }\end{array}$ & Torigoe et al. (2011) \\
\hline & Silver nanoparticles & $\begin{array}{l}\text { Reduction of silver ions in } \mathrm{W} / \mathrm{O} \\
\text { microemulsions }\end{array}$ & Kakazu et al. (2010) \\
\hline \multirow{3}{*}{$\begin{array}{l}\text { Solid lipid } \\
\text { particles }\end{array}$} & W/S microcarrier & $\begin{array}{l}\text { Melt crystallization in } \mathrm{W} / \mathrm{O} / \mathrm{W} \\
\text { emulsion }\end{array}$ & $\begin{array}{l}\text { Kukizaki and Goto } \\
(2007 \mathrm{c})\end{array}$ \\
\hline & $\mathrm{S} / \mathrm{S}$ microcarrier & $\begin{array}{l}\text { Melt crystallization in } \mathrm{S} / \mathrm{O} / \mathrm{W} \\
\text { emulsion }\end{array}$ & Kukizaki (2009c) \\
\hline & Coherent particles & $\begin{array}{l}\text { Melt crystallization in } \mathrm{O} / \mathrm{W} \\
\text { emulsion }\end{array}$ & $\begin{array}{l}\text { D'oria et al. (2009); Li } \\
\text { et al. (2011) }\end{array}$ \\
\hline \multirow{6}{*}{$\begin{array}{l}\text { Gel micro- and } \\
\text { nano-particles }\end{array}$} & Ca-alginate & $\begin{array}{l}\text { Crosslinking of sodium alginate } \\
\text { with } \mathrm{Ca}^{2+} \text { in } \mathrm{W} / \mathrm{O} \text { emulsion }\end{array}$ & $\begin{array}{l}\text { Liu et al. (2003); You } \\
\text { et al. (2001); } \\
\text { Akamatsu et al. (2011) }\end{array}$ \\
\hline & \multirow{2}{*}{ Chitosan } & $\begin{array}{l}\text { Crosslinking of chitosan with } \\
\text { glutaraldehyde in W/O emulsion }\end{array}$ & $\begin{array}{l}\text { Wang et al. (2005); } \\
\text { Wei et al. (2010); Yue } \\
\text { et al. (2011); } \\
\text { Akamatsu et al. (2012) }\end{array}$ \\
\hline & & $\begin{array}{l}\text { Crosslinking of chitosan with } \\
\text { glutaraldehyde in } \mathrm{O} / \mathrm{W} / \mathrm{O} \\
\text { emulsion }\end{array}$ & Wei et al. (2013) \\
\hline & HTCC/GP & $\begin{array}{l}\text { Thermal gelation in } \mathrm{W} / \mathrm{O} \\
\text { emulsion }\end{array}$ & Wu et al. (2008) \\
\hline & Alginate/chitosan & $\begin{array}{l}\text { Coalescence of } \mathrm{Na} \text {-alginate } \\
\text { droplets with } \mathrm{Ca}^{2+} \text { droplets and } \\
\text { particle coating with chitosan }\end{array}$ & Zhang et al. (2011) \\
\hline & Agarose & $\begin{array}{l}\text { Helix-coil transition induced by } \\
\text { cooling }\end{array}$ & $\begin{array}{l}\text { Zhou et al. (2007; } \\
\text { 2008; 2009) }\end{array}$ \\
\hline $\begin{array}{l}\text { Protein } \\
\text { microspheres }\end{array}$ & Albumin & $\begin{array}{l}\text { Heat or chemical denaturation of } \\
\text { albumin in } \mathrm{W} / \mathrm{O} \text { emulsion }\end{array}$ & $\begin{array}{l}\text { El-Mahdy et al. } \\
\text { (1998); Muramatsu } \\
\text { and Kondo (1995); } \\
\text { Muramatsu and } \\
\text { Nakauchi (1998) }\end{array}$ \\
\hline $\begin{array}{l}\text { Composite } \\
\text { organic-inorganic } \\
\text { particles }\end{array}$ & $\begin{array}{l}\text { Polymer particles with } \\
\text { embedded } \mathrm{TiO}_{2} / \mathrm{Fe}_{3} \mathrm{O}_{4} \\
\text { nanoparticles or quantum } \\
\text { dots }\end{array}$ & $\begin{array}{l}\text { Solvent evaporation from oil } \\
\text { phase in } \mathrm{S} / \mathrm{O} / \mathrm{W} \text { emulsion }\end{array}$ & $\begin{array}{l}\text { Supsakulchai et al. } \\
(2002 ; 2002 b) ; \text { Omi et } \\
\text { al. (2001); Wang et al. } \\
\text { (2013); Yang et al. } \\
\text { (2010); Zhou et al. } \\
\text { (2012) }\end{array}$ \\
\hline
\end{tabular}




\begin{tabular}{|c|c|c|c|}
\hline & $\begin{array}{l}\text { Polymeric particles } \\
\text { coated with silica } \\
\text { nanoparticles }\end{array}$ & $\begin{array}{l}\text { Solvent evaporation followed by } \\
\text { electrostatic layer-by-layer } \\
\text { deposition }\end{array}$ & Ito et al. (2010) \\
\hline \multirow{5}{*}{$\begin{array}{l}\text { Coherent } \\
\text { polymeric micro- } \\
\text { or nano-spheres }\end{array}$} & $\begin{array}{l}\mathrm{PSt}, \mathrm{P}(\mathrm{St}-c o-\mathrm{DVB}), \mathrm{P}(\mathrm{St}- \\
\text { co-MMA), PUU-VP, etc. }\end{array}$ & $\begin{array}{l}\text { One-stage suspension } \\
\text { polymerization in } \mathrm{O} / \mathrm{W} \text { emulsion }\end{array}$ & $\begin{array}{l}\text { Yuyama et al. (2000); } \\
\text { Omi et al. (1994); } \\
\text { Nuisin et al. (2000); } \\
\text { Ma et al. (2003); }\end{array}$ \\
\hline & PSt-PAAm composite & $\begin{array}{l}\text { One-stage suspension } \\
\text { polymerisation in } \mathrm{W} / \mathrm{O} / \mathrm{W} \\
\text { emulsion }\end{array}$ & Ma et al. (2004) \\
\hline & $\begin{array}{l}\text { P(AAm-co-AA) and } \\
\text { PNaAMPS hydrogel }\end{array}$ & $\begin{array}{l}\text { One-stage suspension } \\
\text { polymerisation in } \mathrm{W} / \mathrm{O} \text { emulsion }\end{array}$ & $\begin{array}{l}\text { Nagashima et al. } \\
(1998) ; \text { Hu et al. } \\
(2011)\end{array}$ \\
\hline & $\begin{array}{l}\text { PMMA microspheres } \\
\text { and large } \mathrm{P}(\mathrm{St}-\mathrm{co} \text {-DVB) } \\
\text { spheres }\end{array}$ & $\begin{array}{l}\text { Two-stage suspension } \\
\text { polymerisation in } \mathrm{O} / \mathrm{W} \text { emulsion }\end{array}$ & $\begin{array}{l}\text { Omi et al. (1995; } \\
\text { 1997) }\end{array}$ \\
\hline & PUU, PSt-PMMA, & $\begin{array}{l}\text { Solvent evaporation from oil } \\
\text { phase droplets in } \mathrm{O} / \mathrm{W} \text { emulsion }\end{array}$ & $\begin{array}{l}\text { Yuyama et al. } \\
(2000 b) ; \text { Ma et al. } \\
(1999 ; 1999 b ; 1999 c)\end{array}$ \\
\hline \multirow{3}{*}{$\begin{array}{l}\text { Synthetic } \\
\text { biodegradable } \\
\text { polymer particles }\end{array}$} & $\begin{array}{l}\text { Coherent PLA and } \\
\text { PLGA spheres }\end{array}$ & $\begin{array}{l}\text { Solvent evaporation from oil } \\
\text { phase droplets in } \mathrm{O} / \mathrm{W} \text { emulsion }\end{array}$ & $\begin{array}{l}\text { Ito et. (2011); Yue et } \\
\text { al. (2012); Kanakubo } \\
\text { et al. (2010) }\end{array}$ \\
\hline & $\begin{array}{l}\text { PLA or PLGA capsules } \\
\text { for hydrophilic actives, } \\
\text { DFB loaded PLA } \\
\text { capsules }\end{array}$ & $\begin{array}{l}\text { Solvent evaporation from oil } \\
\text { phase in } \mathrm{W} / \mathrm{O} / \mathrm{W} \text { emulsion }\end{array}$ & $\begin{array}{l}\text { Liu et al. (2005; } \\
\text { 2005b; Doan et al. } \\
\text { (2011); Hou et al. } \\
(2009)\end{array}$ \\
\hline & $\begin{array}{l}\text { mPEG-PLA capsules for } \\
\text { hydrophilic actives }\end{array}$ & $\begin{array}{l}\text { Solvent extraction from oil phase } \\
\text { in } \mathrm{W} / \mathrm{O} / \mathrm{W} \text { emulsion }\end{array}$ & $\begin{array}{l}\text { Wei et al. (2008; } \\
\text { 2011) }\end{array}$ \\
\hline \multirow{7}{*}{$\begin{array}{l}\text { Core/shell and } \\
\text { hollow particles }\end{array}$} & $\begin{array}{l}\mathrm{P}(\mathrm{St}-c o-\mathrm{DMAEMA}) \\
\mathrm{P}(\mathrm{St}-c o-\mathrm{DVB}), \mathrm{PDVB}\end{array}$ & $\begin{array}{l}\text { One-stage suspension } \\
\text { polymerisation and internal } \\
\text { phase separation in O/W } \\
\text { emulsion }\end{array}$ & $\begin{array}{l}\text { Ma et al. (2001; 2002; } \\
\text { 2003b); Lee et al. } \\
(2010) ; \text { Hao et al. } \\
(2009)\end{array}$ \\
\hline & $\begin{array}{l}\text { Polymer-supported } \\
\text { palladium catalyst }\end{array}$ & $\begin{array}{l}\text { One-stage suspension } \\
\text { polymerisation, internal phase } \\
\text { separation and ligand exchange }\end{array}$ & $\begin{array}{l}\text { Liu et al. (2010; } \\
\text { 2010b) }\end{array}$ \\
\hline & $\mathrm{P}(\mathrm{St}-c o-\mathrm{DVB}-c o-\mathrm{MAA})$ & $\begin{array}{l}\text { Two-stage suspension } \\
\text { polymerisation and internal } \\
\text { phase separation in O/W } \\
\text { emulsion }\end{array}$ & Wang et al. (2012) \\
\hline & $\begin{array}{l}\text { ENB-P(M-co-U-co-F) } \\
\text { core-shell capsules }\end{array}$ & In situ polymerization & Liu et al. (2011) \\
\hline & Chitosan & $\begin{array}{l}\text { Crosslinking of chitosan onto } \\
\text { alginate particles and core } \\
\text { dissolution }\end{array}$ & Akamatsu et al. (2010) \\
\hline & $\begin{array}{l}\text { Molecularly imprinted } \\
\text { P(MMA-co-EDMA) } \\
\text { particles }\end{array}$ & $\begin{array}{l}\text { Molecular imprinting using CAP } \\
\text { as a template molecule }\end{array}$ & Kou et al. (2012) \\
\hline & $\begin{array}{l}\text { PGPR-PE2CA core-shell } \\
\text { particles }\end{array}$ & $\begin{array}{l}\text { Interfacial polymerization } \\
\text { followed by solvent evaporation }\end{array}$ & Lee et al. (2009) \\
\hline
\end{tabular}




\begin{tabular}{|c|c|c|c|}
\hline & $\begin{array}{l}\text { Hollow porous silica } \\
\text { nanocapsules loaded } \\
\text { with } \mathrm{Fe}_{3} \mathrm{O}_{4} \text { nanoparticles }\end{array}$ & $\begin{array}{l}\text { One-stage suspension } \\
\text { polymerisation, followed by sol- } \\
\text { gel process and calcination }\end{array}$ & $\begin{array}{l}\text { Kong et al. (2010; } \\
2012 ; 2013)\end{array}$ \\
\hline \multirow{2}{*}{$\begin{array}{l}\text { Thermo- } \\
\text { responsive } \\
\text { capsules }\end{array}$} & $\begin{array}{l}\text { Porous PA shells with } \\
\text { P(NIPAM) gates in the } \\
\text { pores }\end{array}$ & Interfacial polymerisation & $\begin{array}{l}\text { Chu et al. (2002; } \\
\text { 2003) }\end{array}$ \\
\hline & $\begin{array}{l}\text { P(NIPAM-co-AA) } \\
\text { capsules }\end{array}$ & $\begin{array}{l}\text { Suspension polymerisation in } \\
\text { W/O emulsion }\end{array}$ & $\begin{array}{l}\text { Si et al. (2011); Wang } \\
\text { et al. (2013) }\end{array}$ \\
\hline \multirow{3}{*}{ Janus particles } & PS/PPC & $\begin{array}{l}\text { Solvent pervaporation and } \\
\text { internal phase separation }\end{array}$ & $\begin{array}{l}\text { Chang and Hatton } \\
(2012)\end{array}$ \\
\hline & $\begin{array}{l}\text { PMMA/P(S-BIEM)- } g- \\
\text { PDMAEMA or } \\
\text { PS/P(MMA-CMS)- } b- \\
\text { PDMAEMA }\end{array}$ & $\begin{array}{l}\text { Solvent evaporation, followed by } \\
\text { internal phase separation and } \\
\text { atom transfer radical } \\
\text { polymerisation }\end{array}$ & $\begin{array}{l}\text { Tanaka et al. (2010); } \\
\text { Ahmad (2008) }\end{array}$ \\
\hline & PS/PMMA & $\begin{array}{l}\text { Solvent evaporation followed by } \\
\text { internal phase separation }\end{array}$ & $\begin{array}{l}\text { Yamashita et al. } \\
(2012)\end{array}$ \\
\hline $\begin{array}{l}\text { Complex } \\
\text { coacervate } \\
\text { microcapsules }\end{array}$ & $\begin{array}{l}\text { gelatin/acacia } \\
\text { microcapsules }\end{array}$ & $\begin{array}{l}\text { Complex coacervation in } \mathrm{O} / \mathrm{W} \\
\text { emulsion }\end{array}$ & Kage et al. (1997) \\
\hline $\begin{array}{l}\text { Non-spherical } \\
\text { particles }\end{array}$ & $\begin{array}{l}\text { hemispherical polymer } \\
\text { particles }\end{array}$ & Cleavage of Janus particles & $\begin{array}{l}\text { Yamashita et al. } \\
(2012)\end{array}$ \\
\hline $\begin{array}{l}\text { 3D colloidal } \\
\text { assemblies }\end{array}$ & $\begin{array}{l}\text { Clusters containing } \\
\text { silica-encapsulated } \\
\text { magnetite nanoparticles }\end{array}$ & $\begin{array}{l}\text { Solvent pervaporation and } \\
\text { coating of clusters with silica }\end{array}$ & $\begin{array}{l}\text { Chang and Hatton } \\
\text { (2012) }\end{array}$ \\
\hline
\end{tabular}

Abbrevations: AA, acrylic acid; DMAEMA, dimethylaminoethyl methacrylate; CAP, chloramphenicol; CMS, chloromethylstyrene; DFB, decafluorobutane; DVB, divinylbenzene; EDMA, ethylene dimethacrylate; ENB 5-ethylidene-2-norbornene; HTCC, $N$-[(2hydroxy-3-trimethylammonium) propyl] chitosan chloride; GP, glycerophosphate; MAA, methacrylic acid; MMA, methyl methacrylate; mPEG, poly(monomethoxypoly ethylene glycol); NIPAM, N-isopropylacrylamide; PAAm, PAAm: polyacrylamide; PE2CA, poly(ethyl 2-cyanoacrylate); PLA, polylactic acid or polylactide; PLGA, poly(lactic-coglycolic acid); P(M-co-U-co-F), Poly(melamine-co-urea-co-formaldehyde); PNaAMPS, poly(sodium 2-(acrylamido)-2-methylpropanesulfonate); PPC, poly(propylene carbonate); P(S-BIEM), poly(styrene-2-(2-bromoisobutyryloxy)ethyl methacrylate; PUU, polyurethaneurea; St, styrene; TPP, tripolyphosphate; VP, vinyl polymer. 


\section{References}

Ahmad, H., Saito, N., Kagawa, Y. and Okubo, M. (2008) 'Preparation of micrometer-sized, monodisperse "Janus" composite polymer particles having temperature-sensitive polymer brushes at half of the surface by seeded atom transfer radical polymerization', Langmuir, 24: 688-691.

Akamatsu, K., Chen, W., Suzuki, Y., Ito, T., Nakao, A., Sugawara, T., Kikuchi, R. and Nakao, S. (2010) 'Preparation of monodisperse chitosan microcapsules with hollow structures using the SPG membrane emulsification technique', Langmuir, 26: 14854-14860.

Akamatsu, K., Ikeuchi, Y., Nakao, A. and Nakao, S. (2012) 'Size-controlled and monodisperse enzyme-encapsulated chitosan microspheres developed by the SPG membrane emulsification technique', J. Colloid Interface Sci., 363: 707-710.

Kazuki Akamatsu, Kaho Maruyama, Wei Chen, Aiko Nakao, Shin-ichi Nakao (2011) 'Drastic difference in porous structure of calcium alginate microspheres prepared with fresh or hydrolyzed sodium alginate', J. Colloid Interface Sci., 371: 46-51.

Anna, S.L., Bontoux, N. and Stone, H.A. (2003) 'Formation of dispersions using “'flow focusing'" in microchannels', Appl. Phys. Lett., 82: 364-366.

Chang, E.P. and Hatton, T.A. (2012) 'Membrane emulsification and solvent pervaporation processes for the continuous synthesis of functional magnetic and Janus nanobeads', Langmuir, 28: 9748-9758.

Chen, G.G., Luo, G.S., Xu, J.H. and Wang, J.D. (2004) 'Membrane dispersion precipitation method to prepare nanopartials', Powder Technol., 139: 180-185.

Chen, G., Luo, G., Yang, X., Sun, Y. and Wang, J. (2004b) 'Anatase-TiO 2 nano-particle preparation with a micro-mixing technique and its photocatalytic performance', Mater. Sci. Eng. A, 380: 320-325.

Chen, G.G., Luo, G.S., Sun, Y., Xu, J.H. and Wang, J.D. (2004c) 'A ceramic microfiltration tube membrane dispersion extractor', AIChE J., 50: 382-387.

Cheng, C.J., Chu, L.Y., Xie, R. and Wang, X.W. (2008) 'Preparation of highly monodisperse W/O emulsions with hydrophobically modified SPG membranes', Chem. Eng. Technol., 31: $377-383$.

Cho, Y.H., Lee, J.J., Park, I.B., Huh, C.S., Baek, Y.J. and Park, J. (2005) 'Protective effect of microencapsulation consisting of multiple emulsification and heat gelation processes on immunoglobulin in yolk', J. Food Sci., 70: E148-E151. 
Choi, Y.K., Poudel, B.K., Marasini, N., Yang, K.Y., Kim, J.W., Kim, J.O., Choi, H.G. and Yong, C.S. (2012) 'Enhanced solubility and oral bioavailability of itraconazole by combining membrane emulsification and spray drying technique', Int. J. Pharm., 434: 264-271. Chu, L.Y., Park, S.H., Yamaguchi, T. and Nakao S. (2002) 'Preparation of micron-sized monodispersed thermoresponsive core-shell microcapsules', Langmuir, 18: 1856-1864. Chu, L.Y., Rui, X., Zhu, J.H., Chen, W.M., Yamaguchi, T. and Nakao, S. (2003) 'Study of SPG membrane emulsification processes for the preparation of monodisperse core-shell microcapsules', J. Colloid Interface Sci., 265: 187-196.

Doan, T.V.P., Couet, W. and Olivier, J.C. (2011) 'Formulation and in vitro characterization of inhalable rifampicin-loaded PLGA microspheres for sustained lung delivery', Int. J. Pharm., 414: 112-117.

D'oria, C., Charcosset, C., Barresi, A.A. and Fessi, H. (2009) 'Preparation of solid lipid particles by membrane emulsification-Influence of process parameters', Colloids Surf., A, 338: 114-118.

Dragosavac, M.M., Holdich, R.G., Vladisavljević, G.T. and Sovilj, M.N. (2012) ‘Stirred cell membrane emulsification for multiple emulsions containing unrefined pumpkin seed oil with uniform droplet size', J. Membr. Sci., 392-393: 122-129.

El-Mahdy, M., Ibrahim, E.S., Safwat, S., el-Sayed, A., Ohshima, H., Makino, K., Muramatsu, N. and Kondo, T. (1998) 'Effects of preparation conditions on the monodispersity of albumin microspheres', J. Microencapsulation, 15: 661-673.

van der Graaf, S., Schroën, C.G.P.H., Van der Sman, R.G.M. and Boom, R.M. (2004)

'Influence of dynamic interfacial tension on droplet formation during membrane emulsification', J. Colloid Interface Sci., 277: 456-463.

Gudipati, V., Sandra, S., McClements, D.J. and Decker, E.A. (2010) 'Oxidative stability and in vitro digestibility of fish oil-in-water emulsions containing multilayered membranes', $J$. Agric. Food Chem., 58: 8093-8099.

Nazir, H., Wang, L., Lian, G., Zhu, S., Zhang, Y., Liu, Y. and Ma, G. (2012) 'Multilayered silicone oil droplets of narrow size distribution: Preparation and improved deposition on hair', Colloids Surf., B, 100: 42-49.

Hao, D.X., Gong, F.L., Hu, G.H., Lei, J.D., Ma, G.H. and Su, Z.G. (2009) 'The relationship between heterogeneous structures and phase separation in synthesis of uniform PolyDVB microspheres', Polymer, 50: 3188-3195. 
Higashi, S. and Setoguchi, T. (2000) 'Hepatic arterial injection chemotherapy for hepatocellular carcinoma with epirubicin aqueous solution as numerous vesicles in iodinated poppy-seed oil microdroplets: clinical application of water-in-oil-in-water emulsion prepared using a membrane emulsification technique', Adv. Drug Deliv. Rev., 45: 57-64.

Hou, Z., Lin, C. and Zhang, Q. (2009) 'Preparation and characterization of PLA ultrasound contrast agents by combining an ultrasound method and a Shirasu Porous Glass (SPG) membrane emulsification technique', 3rd International Conference on Bioinformatics and Biomedical Engineering, 2009. ICBBE 2009.

Hu, J., Hiwatashi, K., Kurokawa, T., Liang, S.M., Wu, Z.L. and Gong, J.P. (2011) 'Microgelreinforced hydrogel films with high mechanical strength and their visible mesoscale fracture structure', Macromolecules, 44: 7775-7781.

Hwang, T., Park, T.J., Koh, W.G., Cheong, I.W., Choi, S.W. and Kim, J.H. (2011)

'Fabrication of nano-scale liposomes containing doxorubicin using Shirasu porous glass membrane', Colloids Surf., A, 392: 250-255.

Ito, F., Uchida, Y. and Murakami, Y. (2010) 'Facile technique for preparing organicinorganic composite particles: Monodisperse poly(lactide-co-glycolide) (PLGA) particles having silica nanoparticles on the surface', Colloids Surf., A, 361: 109-117.

Ito, F., Kanakubo, Y. and Murakami, Y. (2011) 'Rapid preparation of monodisperse biodegradable polymer nanospheres using a membrane emulsification technique under low gas pressure', J. Polym. Res., 18: 2077-2085.

Jaafar-Maalej, C., Charcosset, C. and Fessi, H. (2011) 'A new method for liposome preparation using a membrane contactor', J. Liposome Res., 21: 213-220.

Jing, C., Chin, C.Y. and Xie, R. (2006) 'Preparation of highly monodisperse W/O emulsions with hydrophobically modified SPG membranes', J. Colloid Interface Sci., 300: 375-382. Joscelyne, S.M. and Trägårdh, G. (2000) 'Membrane emulsification - a literature review', $J$. Membr. Sci., 169: 107-117.

Kage, H., Kawahara, H., Ogura, H. and Matsuno, Y. (1997) 'Microencapsulation of monodispersed droplets by complex coacervation method and membrane thickness of generated capsules', Kagaku Kogaku Ronbunshu, 23: 652-658.

Kai, T., Suma, Y., Ono, S., Yamaguchi and Nakao, S. (2006) 'Effect of the pore surface modification of an inorganic substrate on the plasma-grafting behavior of pore-filling-type organic/inorganic composite membranes', J. Polym. Sci., Part A-1: Polym. Chem., 44: 846-856. 
Kakazu, E., Murakami, T., Akamatsu, K., Sugawara, T., Kikuchi, R. and Nakao, S. (2010) 'Preparation of silver nanoparticles using the SPG membrane emulsification technique', $J$. Membr. Sci., 354: 1-5.

Kanakubo, Y., Ito, F. and Murakami, Y. (2010) 'Novel one-pot facile technique for preparing nanoparticles modified with hydrophilic polymers on the surface via block polymer-assisted emulsification/evaporation process', Colloids Surf., B, 78: 85-91.

Kandori, K., Kishi, K. and Ishikawa T. (1992) 'Preparation of uniform silica hydrogel particles by SPG filter emulsification method', Colloids Surf., 62: 259-262.

Karbstein, H. and Schubert H. (1995) 'Developments in the continuous mechanical production of oil-water macro-emulsions', Chem. Eng. Process., 34: 205-211.

Kawakita, H., Hamamoto, K., Seto, H., Ohto, K., Harada, H. and Inoue, K. (2009) 'Porosity estimation of a membrane filled with dextran produced by immobilized dextransucrase', AIChE J., 55: 275-278.

Kawashima, Y., Hino, T., Takeuchi, H., Niwa, T. and Horibe, K. (1991) 'Shear-induced phase inversion and size control of water/oil/water emulsion droplets with porous membrane', $J$. Colloid Interface Sci., 145: 512-523.

Khayata, N., Abdelwahed, W., Chehna, M.F. Charcosset, C. and Fessi, H. (2012) 'Stability study and lyophilization of vitamin E-loaded nanocapsules prepared by membrane contactor', Int. J. Pharm., 439: 254-259.

Kobayashi, I., Nakajima, M. and Mukataka, S. (2003) 'Preparation characteristics of oil-inwater emulsions using differently charged surfactants in straight-through microchannel emulsification', Colloid. Surf. A, 229: 33-41.

Koga, K., Takarada, N. and Takada, K. (2010) 'Nano-sized water-in-oil-in-water emulsion enhances intestinal absorption of calcein, a high solubility and low permeability compound', Eur. J. Pharm. Biopharm., 74: 223-232.

Koltuniewicz, A.B., Field, R.W. and Arnot, T.C. (1995) 'Cross-flow and dead-end microfiltration of oily-water emulsion. Part I: Experimental study and analysis of flux decline', J. Membr. Sci., 102: 193-207.

Kong, S.D., Zhang, W., Lee, J.H., Brammer, K., Lal, R., Karin, M. and Jin, S. (2010) 'Magnetically vectored nanocapsules for tumor penetration and remotely switchable ondemand drug release', Nano Lett., 10: 5088-5092. 
Kong, S.D., Zhang, W., Lee, J.H., Choi, C., Khamwannah, J., Karin, M. and Jin, S. (2012)

'Externally triggered on-demand drug release and deep tumor penetration', J. Vac. Sci.

Technol., B: Microelectron. Nanometer Struct., 30: 02C102-02C102-7.

Kong, S.D., Choi, C., Khamwannah, J. and Jin, S. (2013) 'Magnetically vectored delivery of cancer drug using remotely on-off switchable nanocapsules', IEEE Trans. Magn., 49: $349-352$.

Koris, A., Piacentini, E., Vatai, G., Bekassy-Molnar, E., Drioli, E. and Giorno, L. (2011) 'Investigation on the effects of a mechanical shear-stress modification method during crossflow membrane emulsification', J. Membr. Sci., 371: 28-36.

Kosvintsev, S.R., Gasparini, G., Holdich, R.G., Cumming, I.W. and Stillwell, M.T. (2005) 'Liquid-liquid membrane dispersion in a stirred cell with and without controlled shear', Ind. Eng. Chem. Res., 44: 9323-9330.

Kosvintsev, S.R., Gasparini, G. and Holdich, R.G. (2008) 'Membrane emulsification: droplet size and uniformity in the absence of surface shear', J. Membr. Sci., 313: 182-189.

Kou, X., Li, Q., Lei, J., Geng, L., Deng, H., Zhang, G., Ma, G., Su, Z. amd Jiang, Q. (2012) 'Preparation of molecularly imprinted nanospheres by premix membrane emulsification technique', J. Membr. Sci., 417-418: 87-95.

Kukizaki, M. and Nakashima, T. (2004) 'Acid leaching process in the preparation of porous glass membranes from phase-separated glass in the $\mathrm{Na}_{2} \mathrm{O}-\mathrm{CaO}-\mathrm{MgO}-\mathrm{Al}_{2} \mathrm{O}_{3}-$ $\mathrm{B}_{2} \mathrm{O}_{3}-\mathrm{SiO}_{2}$ system', Membrane, 29: 301-308.

Kukizaki, M. and Goto, M. (2006) 'Size control of nanobubbles generated from Shirasuporous-glass (SPG) membranes', J. Membr. Sci., 281: 386-396.

Kukizaki, M. and Goto, M. (2007) 'Spontaneous formation behavior of uniform-sized microbubbles from Shirasu porous glass (SPG) membranes in the absence of water-phase flow', Colloids Surf., A, 296: 174-181.

Kukizaki, M. and Goto, M. (2007b) 'Preparation and characterization of a new asymmetric type of Shirasu porous glass (SPG) membrane used for membrane emulsification', J. Membr. Sci., 299: 190-199.

Kukizaki, M. and Goto, M. (2007c) 'Preparation and evaluation of uniformly sized solid lipid microcapsules using membrane emulsification', Colloids Surf., A, 293: 87-94.

Kukizaki, M. and Goto, M. (2008) 'Demulsification of water-in-oil emulsions by permeation through Shirasu-porous-glass (SPG) membranes', J. Membr. Sci., 322: 196-203. 
Kukizaki, M. and Wada, T. (2008) 'Effect of the membrane wettability on the size and size distribution of microbubbles formed from Shirasu-porous-glass (SPG) membranes', Colloids Surf., A, 317: 146-154.

Kukizaki, M. and Goto, M. (2009) 'A comparative study of SPG membrane emulsification in the presence and absence of continuous-phase flow', J. Chem Eng. Jpn, 42: 520-530.

Kukizaki, M. (2009) 'Shirasu porous glass (SPG) membrane emulsification in the absence of shear flow at the membrane surface: Influence of surfactant type and concentration, viscosities of dispersed and continuous phases, and transmembrane pressure', J. Membr. Sci., 327: $234-243$.

Kukizaki, M. (2009b) 'Relation between salt rejection and electrokinetic properties on Shirasu porous glass (SPG) membranes with nano-order uniform pores', Sep. Sci. Technol., 69: 87-96.

Kukizaki, M. (2009c) 'Preparation of solid lipid microcapsules via solid-in-oil-in-water dispersions by premix membrane emulsification', Chem. Eng. J., 151: 387-396.

Kukizaki, M. (2010) 'Large-scale production of alkali-resistant Shirasu porous glass (SPG) membranes: Influence of $\mathrm{ZrO}_{2}$ addition on crystallization and phase separation in $\mathrm{Na}_{2} \mathrm{O}-$ $\mathrm{CaO}-\mathrm{Al}_{2} \mathrm{O}_{3}-\mathrm{B}_{2} \mathrm{O}_{3}-\mathrm{SiO}_{2}$ glasses; and alkali durability and pore morphology of the membranes', J. Membr. Sci., 360: 426-435.

Laouini, A., Jaafar-Maalej, C., Sfar, S., Charcosset, C. and Fessi, H. (2011) 'Liposome preparation using a hollow fiber membrane contactor - application to spironolactone encapsulation', Int. J. Pharm., 415: 53-61.

Lee, S.H., Baek, H.H., Kim, J.H. and Choi, S.W. (2009) 'Core-shell poly(d,l-lactide-coglycolide)/poly(ethyl 2-cyanoacrylate) microparticles with doxorubicin to reduce initial burst release', Macromol. Res., 17: 1010-1014.

Lee, J., Hwang, D.R. and Shim, S.E. (2010) 'Controlling morphology of polymer microspheres by Shirasu porous glass (SPG) membrane emulsification and subsequent polymerization: from solid to hollow', Macromol. Res., 18: 1142-1147.

Li, N. and Sakaki, K. (2008) 'Performance of an emulsion enzyme membrane reactor combined with premix membrane emulsification for lipase-catalyzed resolution of enantiomers', J. Membr. Sci., 314: 183-192.

Li, Y., Fessi, H. and Charcosset, C. (2011) 'Preparation of indomethacin-loaded lipid particles by membrane emulsification', Adv. Sci. Lett., 4: 591-595. 
Liu, X.D., Bao, D.C., Xue, W.M., Xiong, Y., Yu, W.T., Yu, X.J., Ma, X.J. and Yuan, Q. (2003) 'Preparation of uniform calcium alginate gel beads by membrane emulsification coupled with internal gelation', J. Appl. Polym. Sci., 87: 848-852.

Liu, R., Ma, G.H., Meng, F.T. and Su, Z.G. (2005) 'Preparation of uniform-sized PLA microcapsules by combining Shirasu Porous Glass membrane emulsification technique and multiple emulsion-solvent evaporation method', J. Controlled Release, 103: 31-43.

Liu, R., Ma, G.H., Wan, Y.H. and Su, Z.G. (2005b) 'Influence of process parameters on the size distribution of PLA microcapsules prepared by combining membrane emulsification technique and double emulsion-solvent evaporation method', Colloids Surf., B, 45: 144-153. Liu, Y., Feng, X.J., Bao, D.C., Li, K.X. and Bao, M. (2010) 'Preparation of microcapsulesupported palladium catalyst using SPG (Shirasu Porous Glass) emulsification technique', Chin. Chem. Lett., 21: 979-982.

Liu, Y., Feng, X.J., Bao, D.C., Li, K. and Bao, M. (2010b) 'A new method for the preparation of microcapsule-supported palladium catalyst for Suzuki coupling reaction', J. Mol. Catal. A: Chem., 323: 16-22.

Liu, X., Lee, J.K. and Kessler, M.R. (2011) 'Microencapsulation of self-healing agents with melamine-urea-formaldehyde by the Shirasu porous glass (SPG) emulsification technique', Macromol. Res., 19: 1056-1061.

Liu, C., Tanaka, H., Zhang, L., Zhang, J., Huang, X., Ma, J. and Matsuzawa, Y. (2012) 'Fouling and structural changes of Shirasu porous glass (SPG) membrane used in aerobic wastewater treatment process for microbubble aeration', J. Membr. Sci., 421-422: 225-231. Liu, C., Tanaka, H., Ma, J., Zhang, L., Zhang, J., Huang, X. and Matsuzawa, Y. (2012b) 'Effect of microbubble and its generation process on mixed liquor properties of activated sludge using Shirasu porous glass (SPG) membrane system', Water Res., 46: 6051-6058. Liu, C., Tanaka, H., Zhang, J., Zhang, L., Yang, J., Huang, X. and Kubota, N. (2013) 'Successful application of Shirasu porous glass (SPG) membrane system for microbubble aeration in a biofilm reactor treating synthetic wastewater', Sep. Purif. Technol., 103: 53-59. Laouini, A., Fessi, H. and Charcosset, C. (2012) 'Membrane emulsification: A promising alternative for vitamin E encapsulation within nano-emulsion', J. Membr. Sci., 423-424: $85-96$.

Ma, G.H., Nagai, M. and Omi, S. (1999) 'Study on preparation and morphology of uniform artificial polystyrene-poly(methyl methacrylate) composite microspheres by employing the SPG (Shirasu Porous Glass) membrane emulsification technique', J. Colloid Interface Sci., 
214: 264-282.

Ma, G.H., Nagai, M. and Omi, S. (1999b) 'Effect of lauryl alcohol on morphology of uniform polystyrene-poly(methyl methacrylate) composite microspheres prepared by Porous glass membrane emulsification technique', J. Colloid Interface Sci., 219: 110-128.

Ma, G.H., Nagai, M. and Omi, S. (1999c) 'Preparation of uniform poly(lactide) microspheres by employing the shirasu porous glass (SPG) emulsification technique', Colloids Surf. A, 153: 383-394.

Ma, G.H., Nagai, M. and Omi, S. (2001) 'Study on preparation of monodispersed poly(styrene-co-N-dimethylaminoethyl methacrylate) composite microspheres by SPG (shirasu porous glass) emulsification technique', J. Appl. Polym. Sci., 79: 2408-2424. Ma, G.H., Omi, S., Dimonie, V.L., Sudol, E.D. and El-Aasser, M.S. (2002) 'Study of the preparation and mechanism of formation of hollow monodisperse polystyrene microspheres by SPG (Shirasu Porous Glass) emulsification technique', J. Appl. Polym. Sci., 85: $1530-1543$.

Ma, G.H., An, C.J., Yuyama, H., Su, Z.G. and Omi, S. (2003) 'Synthesis and characterization of polyurethaneurea-vinyl polymer (PUU-VP) uniform hybrid microspheres by SPG emulsification technique and subsequent suspension polymerization', J. Appl. Polym. Sci., 89: $163-178$.

Ma, G.H., Chen, A.Y., Su, Z.G. and Omi, S. (2003b) 'Preparation of uniform hollow polystyrene particles with large voids by a glass-membrane emulsification technique and a subsequent suspension polymerization', J. Appl. Polym. Sci., 87: 244-251.

Ma, G.H., Sone, H. and Omi, S. (2004) 'Preparation of uniform-sized polystyrenepolyacrylamide composite microspheres from a W/O/W emulsion by membrane emulsification technique and subsequent suspension polymerization', Macromolecules, 37: 2954-2964.

Mazzei, R., Drioli, E. and Giorno, L. (2010) 'Biocatalytic membrane reactor and membrane emulsification concepts combined in a single unit to assist production and separation of water unstable reaction products', J. Membr. Sci., 352: 166-172.

Meng, T., Xie, R., Chen, Y.C., Cheng, C.J., Li, P.F., Ju, X.J. and Chu, L.Y. (2010) ‘A thermo-responsive affinity membrane with nano-structured pores and grafted poly $(\mathrm{N}$ isopropylacrylamide) surface layer for hydrophobic adsorption', J. Membr. Sci., 349: 258-267.

Meng, T., Xie, R., Ju, X.J., Cheng, C.J., Wang, S., Li, P.F., Liang, B. and Chun, L.Y. (2013) 
'Nano-structure construction of porous membranes by depositing nanoparticles for enhanced surface wettability', J. Membr. Sci., 427: 63-72.

Mulder, M. (1996) Basic Principles of Membrane Technology, Dordrecht: Kluwer Academic Publishers.

Muramatsu, N. and Kondo, T. (1995) 'An approach to prepare microparticles of uniform size', J. Microencapsulation, 2: 129-136.

Muramatsu, N. and Nakauchi, K. (1998) 'A novel method to prepare monodisperse microparticles', J. Microencapsulation, 15: 715-723.

Nagashima, S., Ando, S., Tsukamoto, T., Ohshima, H. and Makino, K. (1998) 'Preparation of monodisperse poly(acrylamide-co-acrylic acid) hydrogel microspheres by a membrane emulsification technique and their size-dependent surface properties', Colloids Surf., B, 11: $47-56$

Nakashima, T. and Kuroki, Y. (1981) 'Effect of composition and heat treatment on the phase separation of $\mathrm{NaO}-\mathrm{B}_{2} \mathrm{O}_{3}-\mathrm{SiO}_{2}-\mathrm{Al}_{2} \mathrm{O}_{3}-\mathrm{CaO}$ glass prepared from volcanic ashes', Nippon Kagaku Kaishi, 8: 1231-1238.

Nakashima T. and Shimizu M. (1986) 'Porous glass from calcium alumino boro-silicate glass', Ceramics Japan, 21: 408-412.

Nakashima T., Shimizu M. and Kukizaki, M. (1991) 'Membrane emulsification by microporous glass', Key Eng. Mater., 61-62: 513-516.

Nakashima, T., Shimizu, M. and Kukizaki M. (1992) 'Mechanical strength and thermal resistance of porous glass', J. Ceram. Soc. Jpn. Int. Ed., 100: 1389-1393.

Nakashima, T., Shimizu, M. and Kukizaki M. (1993) 'Effect of surfactant on production of monodispersed O/W emulsion in membrane emulsification', Kag. Kog. Ronbunshu, 19: 991-997.

Nakashima, T., Shimizu, M. and Kukizaki M. (1994) 'Monodisperse single and double emulsions and method of producing same', US Patent 5,326,484.

Nakashima, T., Shimizu, M. and Kukizaki, M. (2000) 'Particle control of emulsion by membrane emulsification and its applications', Adv. Drug Deliv. Rev., 45: 47-56.

Nakashima, T. (2002) 'Porous glass material and its recent applications', paper presented at $38^{\text {th }}$ International SPG Forum on Membrane and Particle Science and Technology in Food and Medical Care in Sadowara, Japan.

Nazir, A., Schroën, K. and Boom, R. (2010) 'Premix emulsification: A review', J. Membr. Sci., 362: 1-11. 
Nuisin, R., Ma, G.H., Omi, S. and Kiatkamjornwong, S.J. (2000) 'Dependence of morphological changes of polymer particles on hydrophobic/hydrophilic additives', J. Appl. Polym. Sci., 77: 1013-1028.

Oh, D.H., Balakrishnan, P., Oh, Y.K., Kim, D.D., Yong, C.S. and Choi, H.G. (2011) 'Effect of process parameters on nanoemulsion droplet size and distribution in SPG membrane emulsification', Int. J. Pharm., 404: 191-197.

Oh, D.H., Din, F.U., Kim, D.W., Kim, J.O., Yong, C.S. and Choi, H.G. (2013) 'Flurbiprofenloaded nanoparticles prepared with polyvinylpyrrolidone using Shirasu porous glass membranes and a spray-drying technique: nano-sized formation and improved bioavailability', J. Microencapsulation, DOI: 10.3109/02652048.2013.774447. Okhonin V., Petrov, A.P., Krylova, S.M. and Krylov, S.N. (2011) 'Quantitative characterization of micromixing based on uniformity and overlap', Angew. Chem. Int. Ed., 50: 11999-12002.

Olson, F., Hunt, C.A. and Szoka, F.C. (1979) 'Preparation of liposomes of defined size distribution by extrusion through polycarbonate membranes', Biochim. Biophys. Acta, 557: 9-23.

Omi, S., Katami, K., Yamamoto, A. and Iso, M. (1994) 'Synthesis of polymeric microspheres employing SPG emulsification technique', J. Appl. Polym. Sci., 51: 1-11.

Omi, S., Katami, K., Taguchi, T., Kaneko, K. and Iso, M. (1995) 'Synthesis of uniform PMMA microspheres employing modified SPG (Shirasu Porous Glass) emulsification technique', J. Appl. Polym. Sci., 57: 1013-1024.

Omi, S., Taguchi, T, Nagai, M. and Ma, G.H. (1997) 'Synthesis of $100 \mu \mathrm{m}$ uniform porous spheres by SPG emulsification with subsequent swelling of the droplets', J. Appl. Polym. Sci., 63: 931-942.

Omi, S., Kanetaka, A., Shimamori, Y., Supsakulchai, A., Nagai, M. and Ma, G.H. (2001) 'Magnetite $\left(\mathrm{Fe}_{3} \mathrm{O}_{4}\right)$ microcapsules prepared using a glass membrane and solvent removal', $J$. Microencapsulation, 19: 749-765.

Pham, T.T., Jaafar-Maalej, C., Charcosset, C. and Fessi, H. (2012) 'Liposome and niosome preparation using a membrane contactor for scale-up', Colloids Surf., B, 94: 15-21.

Park, S.H., Yamaguchi, T. and Nakao, S. (2001) 'Cut-off of dilute O/W emulsions through a microfiltration membrane', J. Membr. Sci., 190: 167-178. 
Pawlik, A.K. and Norton, I.T. (2012) 'Encapsulation stability of duplex emulsions prepared with SPG cross-flow membrane, SPG rotating membrane and rotor-stator techniques - A comparison', J. Membr. Sci., 415-416, 459-468.

Pawlik, A.K. and Norton, I.T. (2013) 'SPG rotating membrane technique for production of food grade emulsions', J. Food Eng., 114: 530-537.

Piacentini, E., Giorno, L., Dragosavac, M.M., Vladisavljević, G.T. and Holdich, R.G. 'Microencapsulation of oil droplets using cold water fish gelatine/gum arabic complex coacervation by membrane emulsification', Food Res. Int., submitted.

Pradhan, R., Lee, D.W., Choi, H.G., Yong, C.S. and Kim, J.O. (2013) 'Fabrication of a uniformly sized fenofibrate microemulsion by membrane emulsification', $J$.

Microencapsulation, 30: 42-48.

Rayner, M., Trägårdh, G. and Trägårdh, C. (2005) 'The impact of mass transfer and interfacial expansion rate on droplet size in membrane emulsification processes', Colloids Surf., A, 266: 1-17.

Schröder, V., Behrend, O. and Schubert H. (1998) 'Effect of dynamic interfacial tension on the emulsification process using microporous, ceramic membrane', J. Colloid Interface Sci., 202: 334-340.

Seto, H., Ohto, K. and Kawakita, H. (2011) 'Reversible extension and shrinkage of solventresponsive dextran chains produced by enzymatic reaction', J. Membr. Sci., 370: 76-81. Segura, R., Cierpka, C., Rossi, M., Joseph, S., Bunjes, H. and Kähler, C. (2013) 'Nonencapsulated thermo-liquid crystals for digital particle tracking thermography/velocimetry in microfluidics', Microfluid. Nanofluid., 14:445-456.

Shimoda, M., Miyamae, H., Nishiyama, K., Yuasa, T., Noma, S. and Igura, N. (2011) 'Swirlflow membrane emulsification for high throughput of dispersed phase flux through Shirasu porous glass (SPG) membrane', J. Chem. Eng. Jpn, 44: 1-6.

Si, T., Wang, Y., Wei, W., Lv, P., Ma, G. and Su, Z. (2011) 'Effect of acrylic acid weight percentage on the pore size in poly(N-Isopropyl acrylamide-co-acrylic acid) microspheres', React. Funct. Polym., 71: 728-735.

Sugiura, S., Nakajima, M., Kumazawa, N., Iwamoto, S. and Seki, M. (2002) 'Characterization of spontaneous transformation-based droplet formation during microchannel emulsification', J. Phys. Chem. B, 106: 9405-9409.

Supsakulchai, A., Ma, G.H., Nagai, M. and Omi, S. (2002) 'Microencapsulation of fine titanium dioxide powders from $(\mathrm{S} / \mathrm{O}) / \mathrm{W}$ emulsion with subsequent solvent evaporation', $A C S$ 
Symp. Ser., 801: 260-275.

Supsakulchai, A., Ma, G.H., Nagai, M. and Omi, S. (2002b) 'Uniform titanium dioxide $\left(\mathrm{TiO}_{2}\right)$ microcapsules prepared by glass membrane emulsification with subsequent solvent evaporation', J. Microencapsulation, 19: 425-449.

Surh, J., Vladisavljević, G.T., Mun, S. and McClements, D.J. (2007) 'Preparation and characterization of water/oil and water/oil/water emulsions containing biopolymergelled water droplets', J. Agric. Food Chem., 55: 175-184.

Surh, J., Jeong, Y.G. and Vladisavljević, G.T. (2008) 'On the preparation of lecithinstabilized oil-in-water emulsions by multi-stage premix membrane emulsification', J. Food Eng., 89: 164-170.

Suzuki, K., Shuto, I. and Hagura, Y. (1996) 'Characteristics of the membrane emulsification method combined with preliminary emulsification for preparing corn oil-in-water emulsions', Food Sci. Technol. Int. Tokyo, 2: 43-47.

Suzuki, K., Fujiki, I. and Hagura, Y. (1999) 'Preparation of high concentration of O/W and W/O emulsions by the membrane phase inversion emulsification using PTFE membranes', Food Sci. Technol. Int. Tokyo, 5: 234-238.

Tanaka, T., Okayama, M., Kitayama, Y., Kagawa, Y. and Okubo, M. (2010) 'Preparation of "mushroom-like" janus particles by site-selective surface-initiated atom transfer radical polymerization in aqueous dispersed systems, Langmuir, 26: 7843-7847.

Tasaki, T., Wada, T., Fujimoto, K., Kai, S. and Ohe, K., Oshima, T., Baba, Y. and Kukizaki, M. (2009), 'Degradation of methyl orange using short-wavelength UV irradiation with oxygen microbubbles', J. Hazard. Mater., 162: 1103-1110.

Thorsen, T., Roberts, R.W., Arnold, F.H. and Quake, S.R. (2001) 'Dynamic pattern formation in a vesicle-generating microfluidic device', Phys. Rev. Lett., 86: 4163-4166.

Torigoe, K., Shimizu, M., Yamamoto, K., Mizozoe, M., Takahashi, H., Suzuki, T. and Murase, M. (2011) 'Method and apparatus for manufacturing low melting point metal fine particles', US patent 7,976,608, 12 July 2011.

Vladisavljević, G.T. and Schubert, H. (2002) 'Preparation and analysis of oil-in-water emulsions with a narrow droplet size distribution using Shirasu-porous-glass (SPG) membranes', Desalination, 144: 167-172.

Vladisavljević, G.T. and Schubert, H. (2003a) 'Preparation of emulsions with a narrow particle size distribution using microporous $\alpha$-alumina membranes', J. Dispersion Sci. Technol., 24: 811-819. 
Vladisavljević, G.T. and Schubert, H. (2003b) 'Influence of process parameters on droplet size distribution in SPG membrane emulsification and stability of prepared emulsion droplets', J. Membr. Sci., 225: 15-23.

Vladisavljević, G.T., Lambrich, U., Nakajima M. and Schubert H. (2004) 'Production of O/W emulsions using SPG membranes, ceramic $\alpha-\mathrm{Al}_{2} \mathrm{O}_{3}$ membranes, microfluidizer and a microchannel plate: a comparative study', Colloids Surf., A, 232: 199-207.

Vladisavljević, G.T., Shimizu, M. and Nakashima, T. (2004b) 'Preparation of monodisperse multiple emulsions at high production rates by multi-stage premix membrane emulsification', J. Membr. Sci., 244: 97-106.

Vladisavljević, G.T., Shimizu, M. and Nakashima, T. (2005) 'Permeability of hydrophilic and hydrophobic Shirasu-porous-glass (SPG) membranes to pure liquids and its microstructure', $J$. Membr. Sci., 250, 69-77.

Vladisavljević, G.T. and Williams, R.A. (2005) 'Recent developments in manufacturing emulsions and particulate products using membranes', Adv. Colloid Interface Sci., 113, 1-20. Vladisavljević, G.T. and Williams, R.A. (2006) 'Manufacture of large uniform droplets using rotating membrane emulsification', J. Colloid Interface Sci., 299: 396-402.

Vladisavljević, G.T., Shimizu, M. and Nakashima, T. (2006) 'Production of multiple emulsions for drug delivery systems by repeated SPG membrane homogenization: Influence of mean pore size, interfacial tension and continuous phase viscosity', J. Membr. Sci., 284: $373-383$.

Vladisavljević, G.T., Surh, J. and McClements, D.J. (2006b) 'Effect of emulsifier type on droplet disruption in repeated Shirasu porous glass membrane homogenization', Langmuir, 22: $4526-4533$.

Vladisavljević, G.T., Kobayashi, I., Nakajima, M., Williams, R.A., Shimizu, M. and Nakashima, T. (2007) 'Shirasu Porous Glass membrane: Characterisation of microstructure by high resolution x-ray microtomography and visualisation of droplet formation in real time', J. Membr. Sci., 302: 243-253.

Vladisavljević, G.T. and Williams, R.A. (2008) 'Recent developments in manufacturing particulate products from double-emulsion templates using membrane and microfluidic devices', in Aserin, A. (ed.), Multiple Emulsions: Technology and Applications, Hoboken: John Wiley \& Sons, Inc.

Vladisavljević, G.T. and Williams, R.A. (2010) 'Recent developments in manufacturing nanoparticles from emulsion droplets', in Starov, V. (ed.), Nanoscience: Colloidal and 
Interfacial Aspects, Boca Raton: CRC Press, pp. 437-491.

Vladisavljević, G.T. and McClements, D.J. (2010) 'Modification of interfacial characteristics of monodisperse droplets produced using membrane emulsification by surfactant displacement and/or polyelectrolyte electrostatic deposition', Colloids Surf., A, 364: 123-131. Vladisavljević, G.T., Kobayashi, I. and Nakajima, M. (2012) 'Production of uniform droplets using membrane, microchannel and microfluidic emulsification devices', Microfluid. Nanofluid., 13: 151-178.

Wang, L.Y., Ma, G.H. and Su, Z.G. (2005) 'Preparation of uniform sized chitosan microspheres by membrane emulsification technique and application as a carrier of protein drug', J. Controlled Release, 106: 62-75.

Wang, Y., Zhang, C., Bi, S. and Luo, G. (2010) 'Preparation of ZnO nanoparticles using the direct precipitation method in a membrane dispersion micro-structured reactor', Powder Technol., 202: 130-136.

Wang, G., Dou, H. and Sun, K. (2012) 'Facile synthesis of hollow polymeric microparticles possessing various morphologies via seeded polymerization', Colloid Polym. Sci., 290: 18671877.

Wang, G., Leng, Y., Dou, H., Wang, L., Li, W., Wang, X., Sun, K., Shen, L., Yuan, X., Li, J., Sun, K., Han, J., Xiao, H. and Li, Y. (2013) 'Highly efficient preparation of multiscaled quantum dot barcodes for multiplexed hepatitis B detection', ASC Nano, 7: 471-481. Wang, Y., Qin, J., Yi, W., Li, C. and Ma, G. (2013) 'Preparation strategies of thermosensitive P(NIPAM-co-AA) microspheres with narrow size distribution', Powder Technol., 236: 107-113.

Wei, Q., Wei, W., Tian, R., Wang, L.Y., Su, Z.G. and Ma, G.H. (2008) 'Preparation of uniform-sized PELA microspheres with high encapsulation efficiency of antigen by premix membrane emulsification', J. Colloid Interface Sci., 323: 267-273.

Wei, W., Ma, G.H., Wang, L.Y., Wu, J. and Su, Z.G. (2010) 'Hollow quaternized chitosan microspheres increase the therapeutic effect of orally administered insulin', Acta Biomater., 6: 205-209.

Wei, Y., Wang, Y., Wang, L., Hao, D. and Ma, G.H. (2011) 'Fabrication strategy for amphiphilic microcapsules with narrow size distribution by premix membrane emulsification', Colloids Surf., B, 87: 399-408.

Wei W., Lv, P.P., Chen, X.M., Yue, Z.G., Fu, Q., Liu, S.Y., Yue, H., and Ma, G.H. (2013) 
'Codelivery of mTERT siRNA and paclitaxel by chitosan-based nanoparticles promoted synergistic tumor suppression', Biomaterials, 34: 3912-3923.

Wu, J., Wei, W., Wang, L.Y., Su, Z.G. and Ma, G.H. (2008) 'Preparation of uniform-sized $\mathrm{pH}$-sensitive quaternized chitosan microsphere by combining membrane emulsification technique and thermal-gelation method', Colloids Surf., B, 63: 164-175.

Xu, J.H., Luo, G.S., Chen, G.G. and Tan, B. (2005) 'Mass transfer performance and twophase flow characteristic in membrane dispersion mini-extractor', J. Membr. Sci., 249: 75-81. Yamamoto, T., Ohmori, T. and Kim, Y.H. (2010) 'Synthesis of monodisperse carbon cryogel microspheres using membrane emulsification of a phenol-formaldehyde solution', Carbon, 48: 912-928.

Yamashita, N., Konishi, N., Tanaka, T. and Okubo, M. (2012) 'Preparation of hemispherical polymer particles by cleavage of a Janus poly(methyl methacrylate) /polystyrene composite particle, Langmuir, 28: 12886-12892.

Yang, J., Hao, D.X., Bi, C.X., Su, Z.G., Wang, L.Y. and Ma, G.H. (2010) 'Rapid synthesis of uniform magnetic microspheres by combing premix membrane emulsification and in situ formation techniques', Ind. Eng. Chem. Res., 49: 6047-6053.

Yasuda, M., Goda, T., Ogino, H., Glomm, W.R. and Takayanagi, H. (2010) 'Preparation of uniform monomer droplets using packed column and continuous polymerization in tube reactor', J. Colloid Interface Sci., 349: 392-410.

Yobas, L., Martens, S., Ong, W.L. and Ranganathan, N. (2006) 'High-performance flowfocusing geometry for spontaneous generation of monodispersed droplets', Lab Chip, 6: 1073-1079.

You, J.O., Park, S.B., Park, H.Y., Haam, S., Chung, C.H. and Kim, W.S. (2001) 'Preparation of regular sized Ca-alginate microspheres using membrane emulsification method', $J$. Microencapsulation, 18: 521-532.

Yue, Z.G., Wei, W., Lv, P.P., Yue, H., Wang, L.Y., Su, Z.G. and Ma, G.H. (2011): 'Surface charge affects cellular uptake and intracellular trafficking of chitosan-based nanoparticles', Biomacromolecules, 12: 2440-2446.

Yue, H., Wei, W., Fan, B., Yue, Z., Wang, L., Ma, G. and Su, Z. (2012) 'The orchestration of cellular and humoral responses is facilitated by divergent intracellular antigen trafficking in nanoparticle-based therapeutic vaccine, Pharmacol. Res., 65: 189-197.

Yuyama, H., Hashimoto, T., Ma, G.H., Nagai, M. and Omi, S. (2000) 'Mechanism of suspension polymerization of uniform monomer droplets prepared by glass membrane 
(Shirasu Porous Glass) emulsification technique', J. Appl. Polym. Sci., 78: 1025-1043. Yuyama, H., Yamamoto, K., Shirafuji, K., Nagai, M. and Ma, G.H. (2000b) 'Preparation of polyurethaneurea (PUU) uniform spheres by SPG membrane emulsification technique', $J$. Appl. Polym. Sci., 77: 2237-2245.

Zhang, Y., Wei, W., Lv, P., Wang, L. and Ma, G. (2011) 'Preparation and evaluation of alginate-chitosan microspheres for oral delivery of insulin', Eur. J. Pharm. Biopharm., 77: $11-19$.

Zhou, Q.Z., Wang, L.Y., Ma, G.H. and Su, Z.G. (2007) 'Preparation of uniform-sized agarose beads by microporous membrane emulsification technique', J. Colloid Interface Sci., 311: $118-127$.

Zhou, Q.Z., Wang, L.Y., Ma, G.H. and Su, Z.G. (2008) 'Multi-stage premix membrane emulsification for preparation of agarose microbeads with uniform size', J. Membr. Sci., 322: 98-104.

Zhou, Q.Z., Ma, G.H. and Su, Z.G. (2009) 'Effect of membrane parameters on the size and uniformity in preparing agarose beads by premix membrane emulsification', J. Membr. Sci., 326: 694-700.

Zhou, Q., Zhang, M.C., Shuang, C.D., Li, Z.Q. and Li, A.M. (2012) 'Preparation of a novel magnetic powder resin for the rapid removal of tetracycline in the aquatic environment', Chin. Chem. Lett., 23: 745-748.

Zúñiga, R.N. and Aguilera, J.M. (2008) 'Aerated food gels: fabrication and potential applications', Trends Food Sci. Technol., 19: 176-187. van der Zwan, E.A., Schroën, C.G.P.H. and Boom, R.M. (2008) 'Premix membrane emulsification by using a packed layer of glass beads', AIChE J., 54: 2190-2197. 


\section{Figure captions}

Figure 1. A comparison between pressure driven membrane separation and membrane microfluidic processes, where $\mathrm{P}_{1}>\mathrm{P}_{2}$. In a membrane separation process (a), feed stream is split into two product streams of different chemical composition (Mulder, 1996). In a membrane dispersion process (b), two streams (misscible or immisbible) are combined together to form one product stream. Membrane treatment of dispersions (c) involves passing a whole dispersion through the membrane, which results in the modification of the particle size distribution in the original dispersion and/or phase inversion.

Figure 2. Membrane dispersion processes with hydrophilic membrane: (a) Production of O/W emulsion by DME (Nakashima et al., 2000); (b) Production of microbubbles (Kukizaki and Goto, 2007c) and nanobubbles (Kukizaki and Goto, 2006); (c) Production of nanoparticles by membrane micromixing / direct precipitation method (Chen et al., 2004).

Figure 3. Treatment of emulsions using membranes: (a) Production of $\mathrm{O} / \mathrm{W}$ emulsion by PME (Suzuki et al., 1996); (b) Production of W/O emulsion by PME with phase inversion (Suzuki et al., 1999); (c) Demulsification of W/O emulsion (Kukizaki and Goto, 2008).

Figure 4. A flow diagram of different steps involved in the fabrication of Shirasu Porous Glass (SPG) membrane.

Figure 5. Spinodal decomposition of glass induced by cooling mother glass from an initial temperature $T_{1}$ to temperature $T_{2}$ lying in the spinodal region (within the spinodal line). To prevent phase separation via nucleation, a transition from the stable to the spinodal region of the phase diagram must proceed quickly or through the upper critical solution temperature (UCST).

Figure 6. (a) Scanning electron micrograph of the surface of SPG membrane polished with diamond paste and used for visualization of ME by metalographic microscope; (b) X-ray microtomography image of SPG membrane (Vladisavljević et al., 2007). 
Figure 7. Chemical modification of SPG surface by treatment with organosilane compounds: (a) Hydrophobic treatment with monochlorosilanes (TMS - trimethylchlorosilane, ODS octadecyldimethylchlorosilane) (Kai et al., 2006); (b) Introduction of amino groups by amino trialkoxysilanes to render the surface positively charged (APTMS - (3-aminopropyl)trimethoxysilane, APTES - (3-aminopropyl)-triethoxysilane).

Figure 8. (a) A micrograph of droplets formed on the surface of SPG membrane in DME (Vladisavljević et al., 2007); (b) Micrographs of droplets before PME and after passing 5 times through 8- $\mu \mathrm{mSPG}$ membrane (Vladisavljević et al., 2010).

Figure 9. An apparatus for cross flow DME using tubular SPG membrane. During initial start up, a valve $\mathbf{1}$ is open to remove any trapped air from the module (Nakashima et al., 1994).

Figure 10. Introduction of continuous phase in cross-flow module from the tangential direction to improve a dispersed phase flux through the membrane (Shimoda et al., 2010).

Figure 11. External pressure type micro kits available by SPG Techology Co., Ltd (Sadowara, Japan) for (a) DME and (b) PME. The kits are supplied with SPG membrane tube with an effective length of $10-15 \mathrm{~mm}$.

Figure 12. Typical contact angles through the water phase and phase pressures encountered in membrane emulsification: (a) Production of $\mathrm{O} / \mathrm{W}$ emulsion $\left(\theta<90^{\circ}, P_{o}>P_{w}\right)$; (b) Production of W/O emulsion $\left(\theta>90^{\circ}, P_{o}<P_{w}\right)$. The contact angle $\theta$ is the angle measured through the water phase, where a liquid/liquid interface meets a membrane surface $\left(\gamma_{m w}=\right.$ interfacial tension between the membrane and water phase, $\gamma_{m o}=$ interfacial tension between the membrane and oil phase, $\gamma_{w o}=$ interfacial tension between the water and oil phase).

Figure 13. Mean droplet size in DME as a function of transmembrane flux, $J$. Dripping regime is characterised by formation of small droplets at high frequency and occurs at $J<J_{c r}$. Continuous outflow regime is characterised by the formation of large droplets at low frequency and occurs at $J>J_{c r}$. 
Figure 14. Mean droplet size in DME as a function of mean pore size of SPG membrane and shear stress on the membrane surface.

Figure 15. Mean droplet size in PME as a function of mean pore size of SPG membrane (at $\sigma_{w, p}=$ const) and transmembrane flux (at $d_{p}=$ const). For comparison, a relationship between mean droplet size and mean pore size in DME is shown by the dashed line.

Figure 16. The pressure difference used to overcome the hydraulic resistances in the system and interfacial tension force as a function of the number of passes through the membrane at two different transmembrane pressures. Production of W/O/W emulsion using PME at the viscosity of the continuous phase of $126 \mathrm{mPas}$, the concentration of W/O drops in W/O/W emulsion of $10 \mathrm{vol} \%$, the concentration of inner water phase in the W/O emulsion of $10 \mathrm{vol} \%$, and the mean pore size of the membrane of $10.7 \mu \mathrm{m}$ (Vladisavljević et al., 2004).

Figure 17. The effect of the number of passes through the membrane on: (a) transmembrane flux, and (b) median diameter and relative span factor of W/O drops. Production of W/O/W emulsion using PME at different transmembrane pressures (100 or $150 \mathrm{kPa})$, viscosities of the continuous phase (1 or $126 \mathrm{mPa} \cdot \mathrm{s})$ and concentrations of W/O drops in W/O/W emulsion (1 or $20 \mathrm{vol} \%$ ). The mean pore size of the SPG membrane was $10.7 \mu \mathrm{m}$ and the concentration of inner water phase in the W/O emulsion was 30 vol\% (Vladisavljević et al., 2006).

Figure 18. Examples of particles fabricated using SPG membrane emulsification: (a) Doxorubicin (DOX)-loaded liposomes prepared by a film-hydration method combined with repeated SPG membrane homogenization and remote loading of DOX (Hwang et al., 2011); (b) Porous thermoresponsive capsules with poly(N-isopropylacrylamide) (PMIPAM) gates prepared by DME, interfacial polymerisation and plasma-graft pore-filling polymerization (Chu et al., 2002); (c) "Mushroom-like" Janus particles prepared by DME, internal phase separation and surface-initiated atom transfer radical polymerisation (ATRP) (Tanaka et al., 2010); (d) Silica-encapsulated magnetite nanoparticle clusters prepared by DME, solvent pervaporation and sol-gel coating (Chang and Hatton, 2012); (e) PLGA particles coated with silica nanoparticles prepared by layer-by-layer electrostatic deposition of poly(allylamine hydrochloride) (PAH) and silica nanoparticles onto PLGA particles produced by DME (Ito et al., 2010); (f) hemispherical particles produced by cleavage of Janus particles fabricated by 
PME (Yamashita et al., 2012); (g) Porous silica shells loaded with magnetic nanoparticles and anticancer drug prepared by DME, polymerisation of styrene droplets, silica sol-gel coating of PS particles, removing PS core by thermal treatment and drug loading (Kong et al., 2010); (h) Janus PMMA/PS particles produced by DME and evaporation of toluene from homogeneous PMMA/PS/toluene droplets (Yamashita et al., 2012); (i) Chitosan shells prepared by coating chitosan onto alginate particles produced by DME, followed by crosslinking the shell and dissolution of the alginate core (Akamatsu et al., 2010); (j) Magnetic polymer microspheres prepared from W/O/W emulsion by PME followed by chemical coprecipitation of $\mathrm{Fe}_{3} \mathrm{O}_{4}$ within the inner water phase and solvent evaporation (Yang et al., 2010); (k) Droplets of hydrophilic drug solution embedded in solid lipid matrix prepared from W/O/W emulsion by temperature-controlled DME and melt crystallisation (Kukizaki and Goto, 2007c); (1) Surfactant-coated hydrophilic drug nanoparticles embedded in solid lipid matrix prepared from S/O/W emulsions by temperature-controlled PME and melt crystallisation (Kukizaki, 2009). 
(a) Membrane

separation

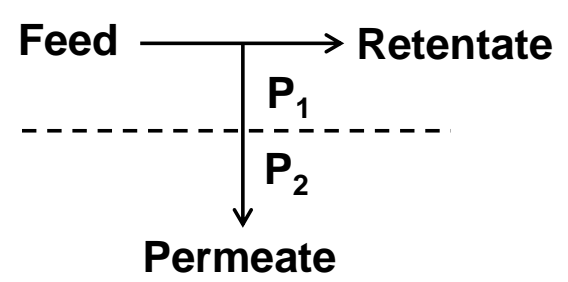

(b) Membrane

dispersion

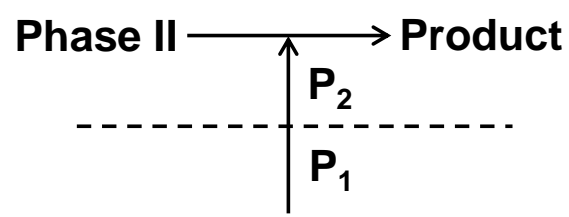

Phase I (c) Treatment of dispersions

Product

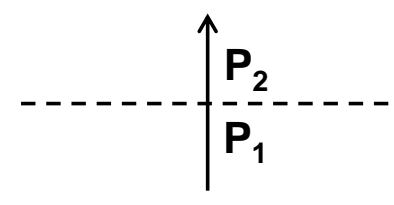

Feed

Figure 1 

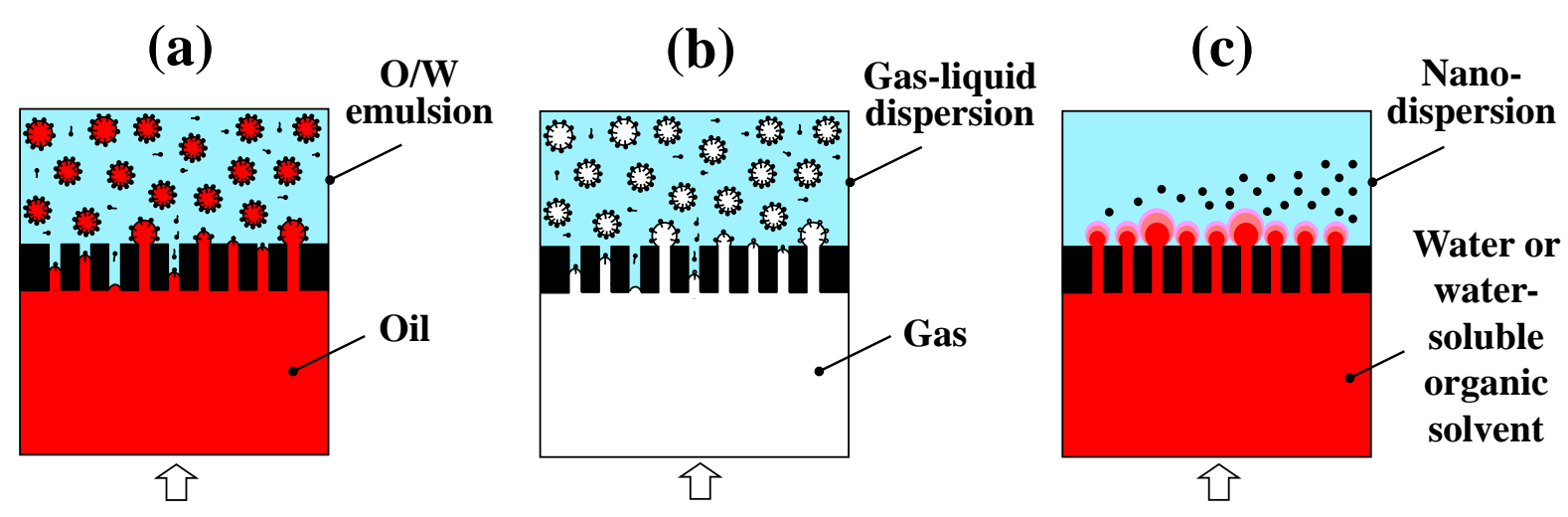

Figure 2 
(a)

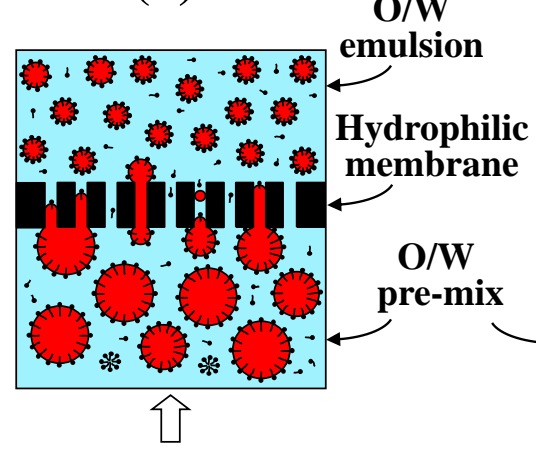

(b)

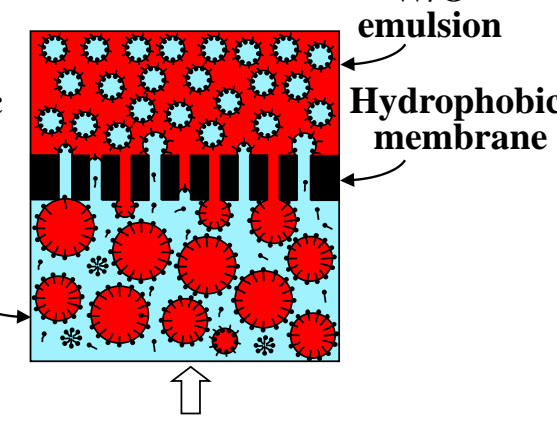

(c)

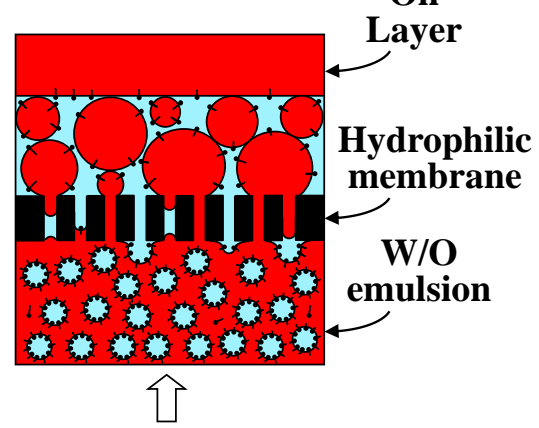

Figure 3 


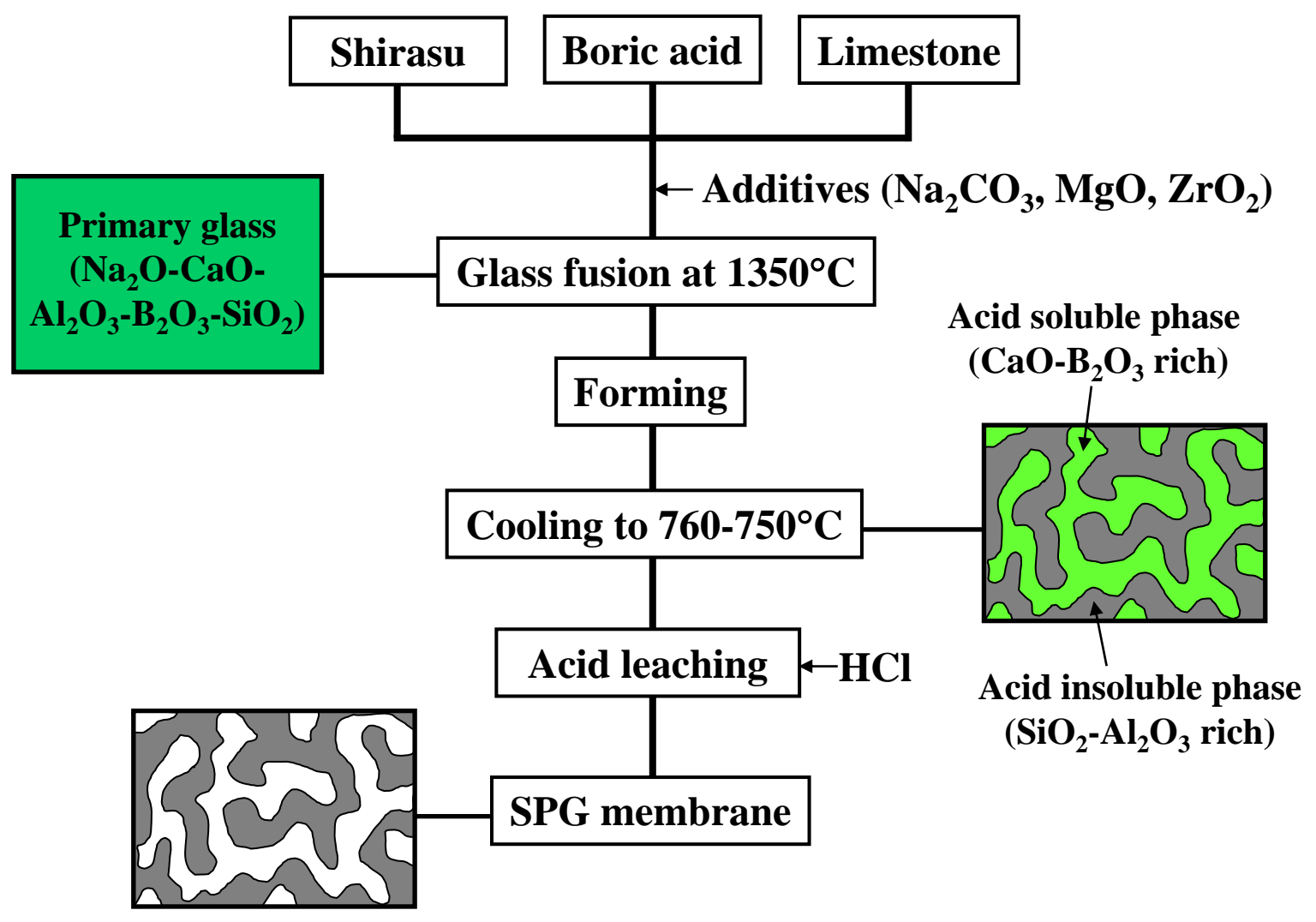

Figure 4 


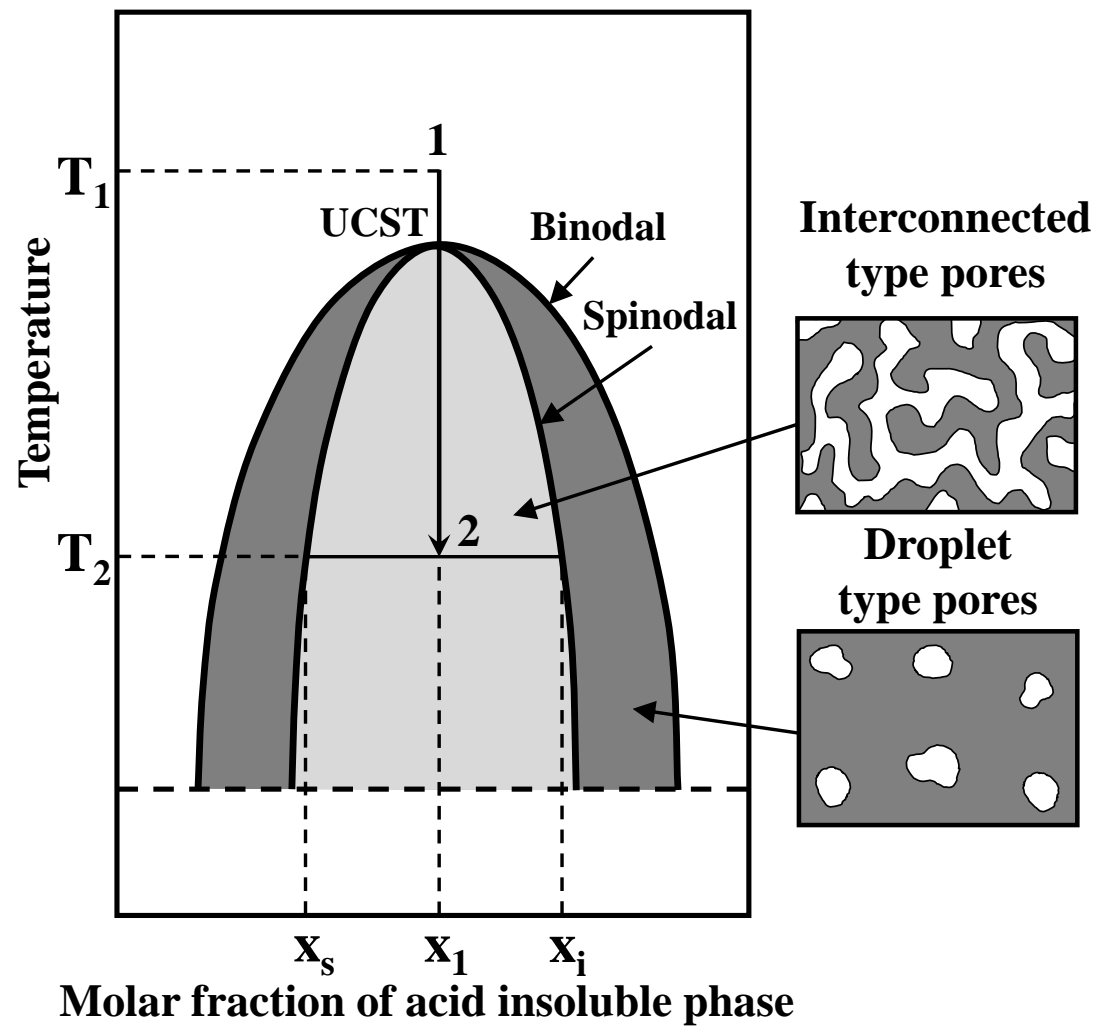

Figure 5 
(a)

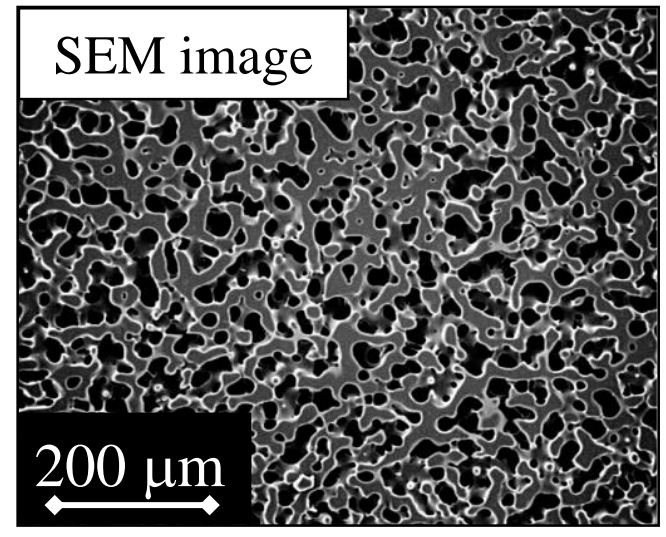

(b)

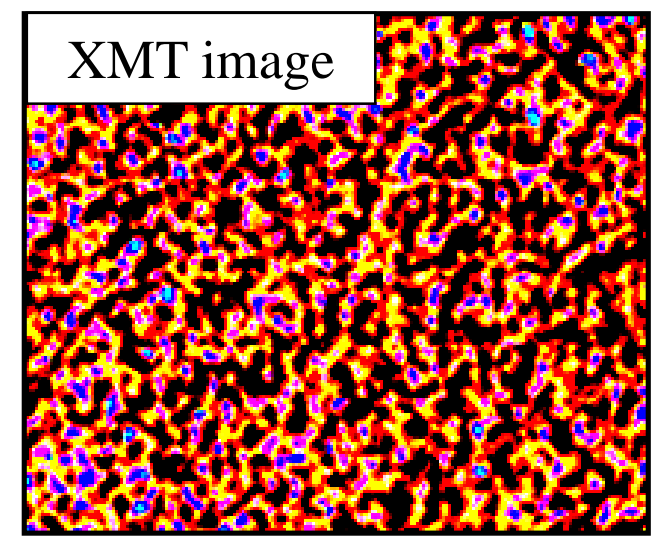

Figure 6 
(a) Treatment with monochlorosilanes (TMS and ODS)

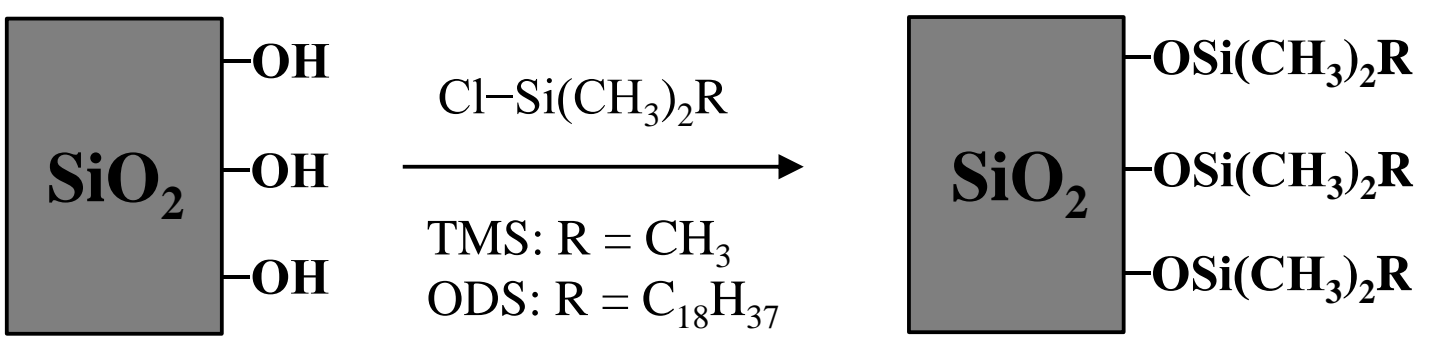

(b) Treatment with amino trialkoxysilanes (APTMS and APTES)

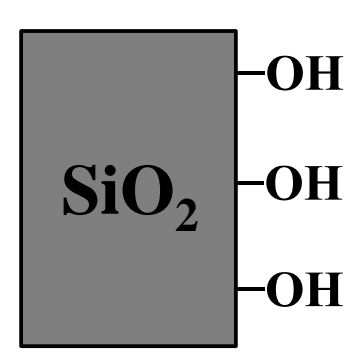

$$
\begin{aligned}
& \stackrel{\mathrm{RO}-\mathrm{Si}}{\mathrm{RO}+\mathrm{NH}_{2} \mathrm{O}} \\
& \stackrel{\mathrm{APTMS}: \mathrm{R}=\mathrm{CH}_{3}}{\longrightarrow} \\
& \text { APTES: } \mathrm{R}=\mathrm{C}_{2} \mathrm{H}_{5}
\end{aligned}
$$

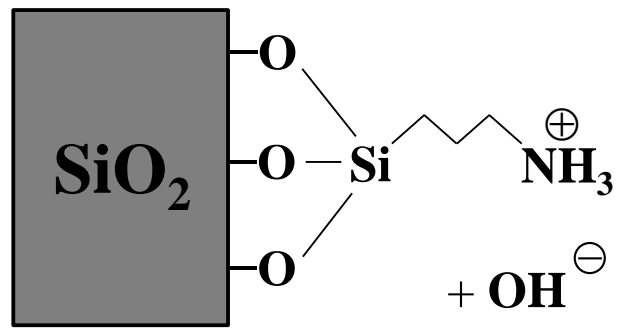

Figure 7 
(a)

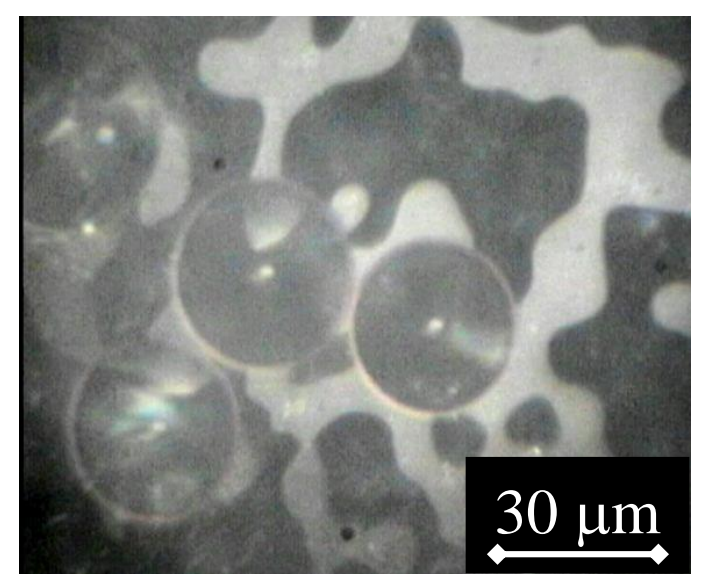

(b)

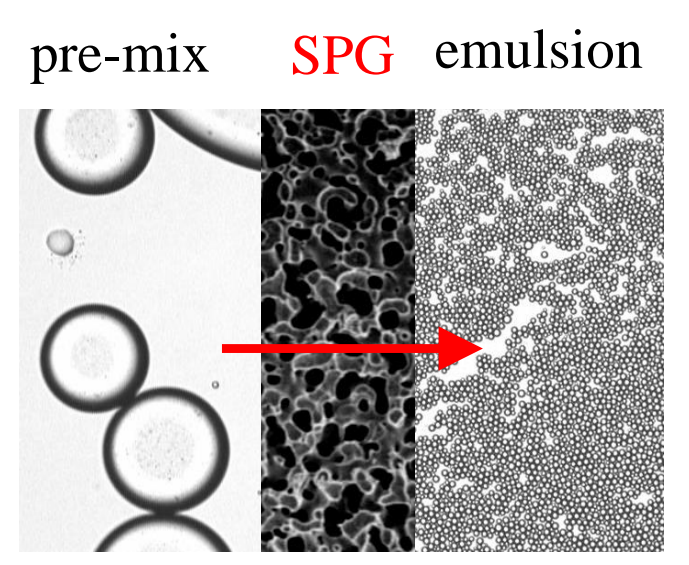

Figure 8 


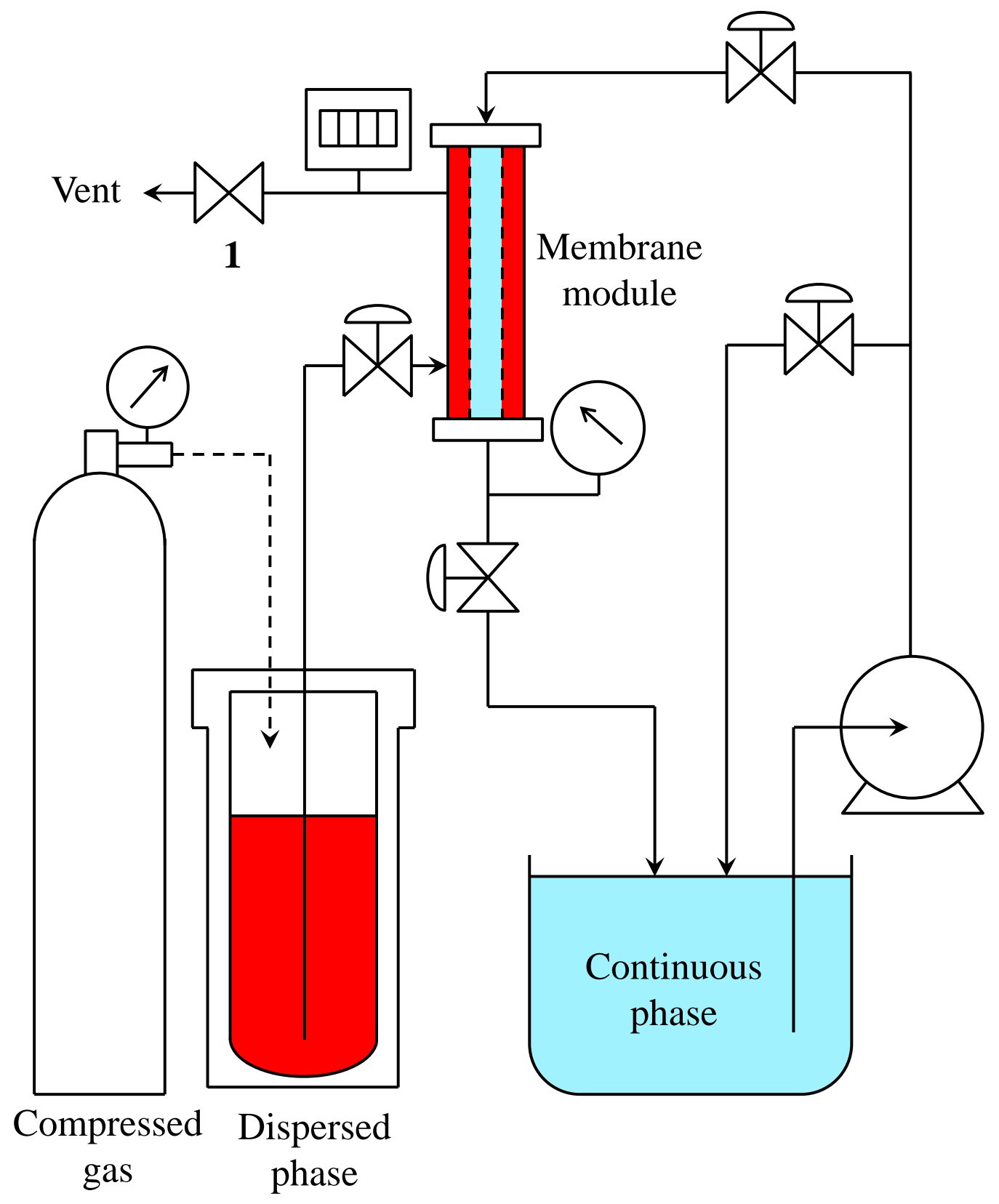

Figure 9 


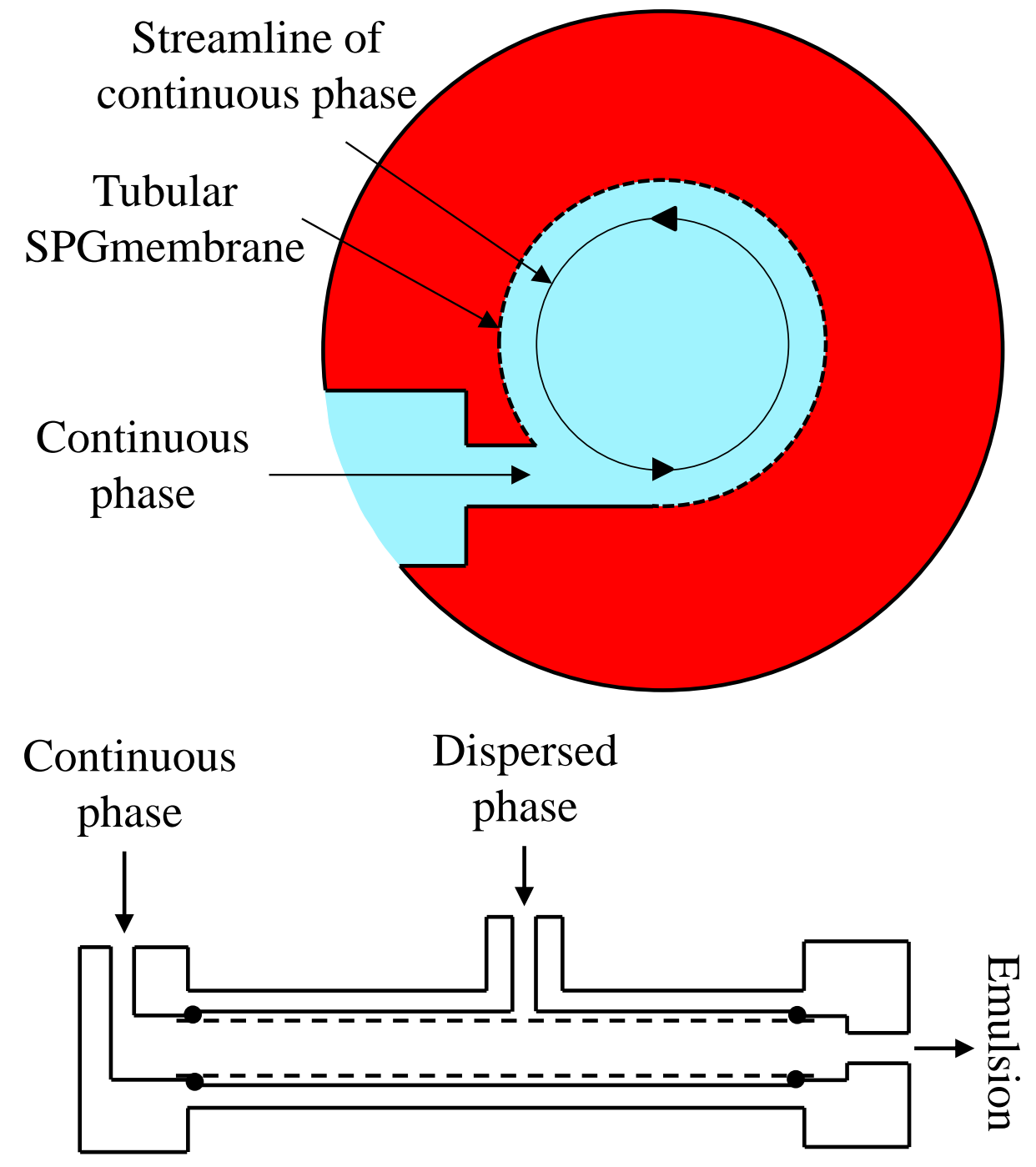

Figure 10 

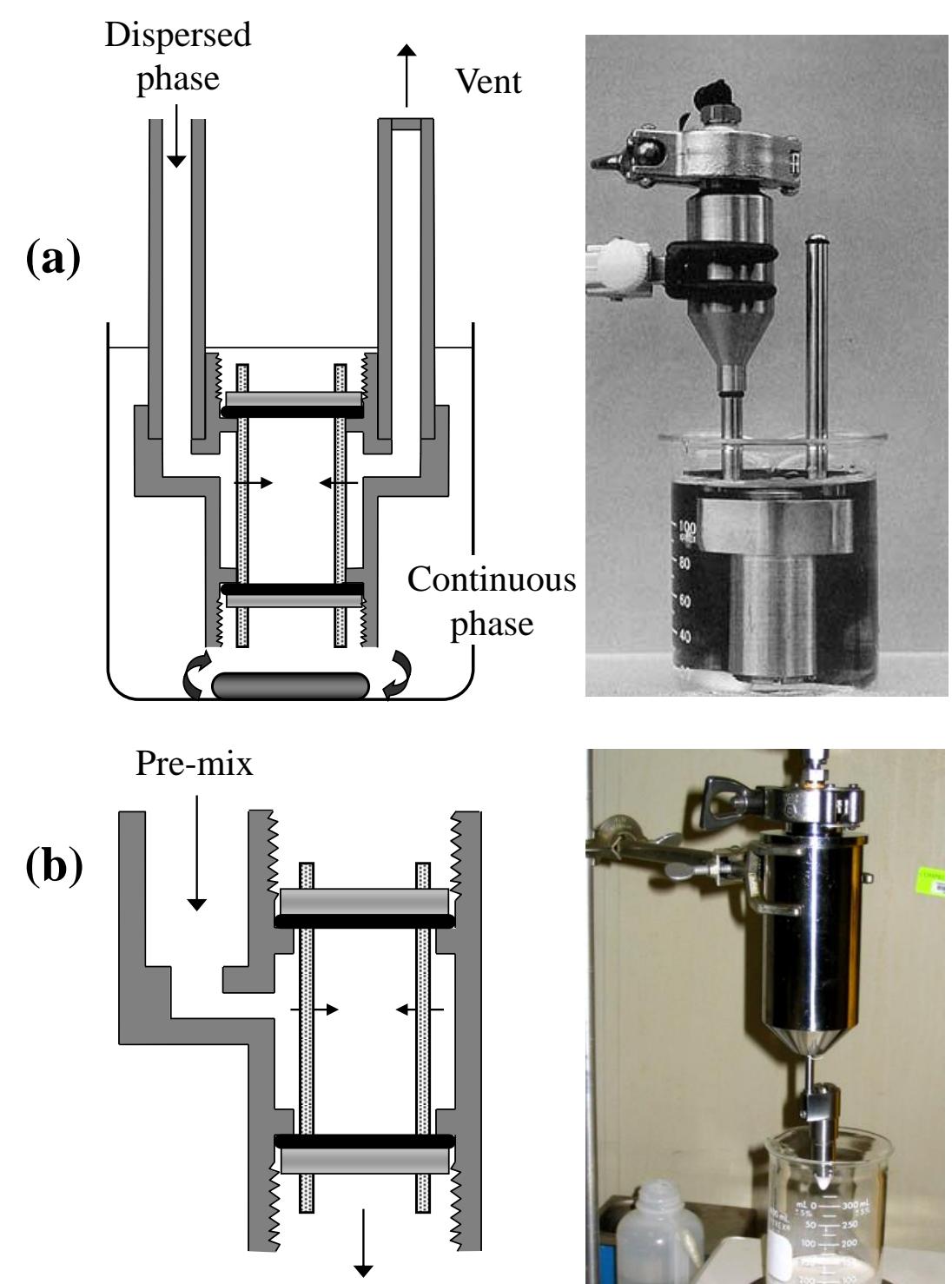

Emulsion

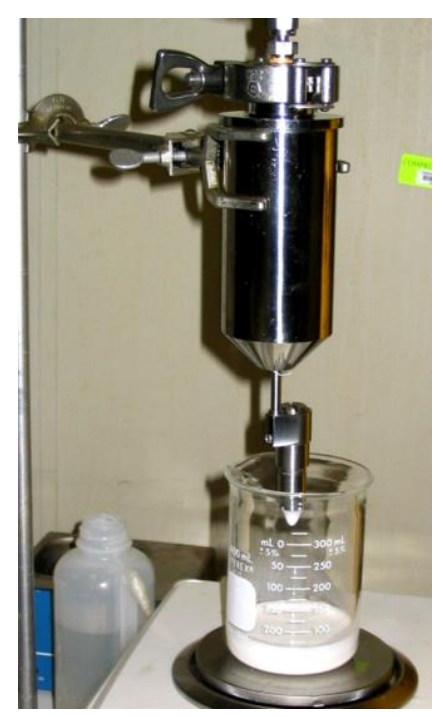

Figure 11 
(a)

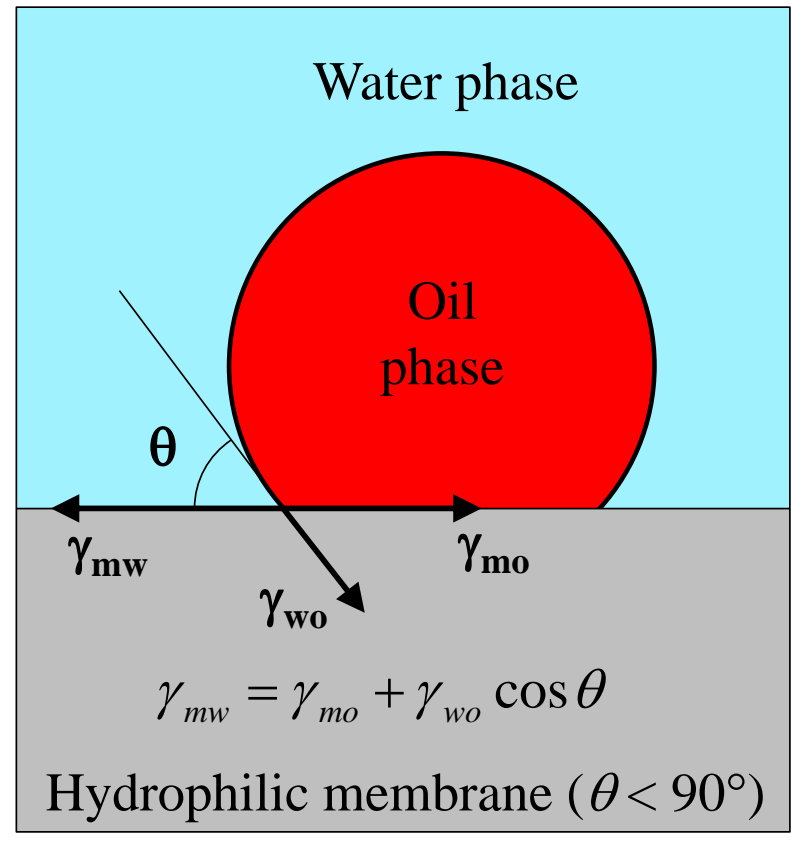

(b)

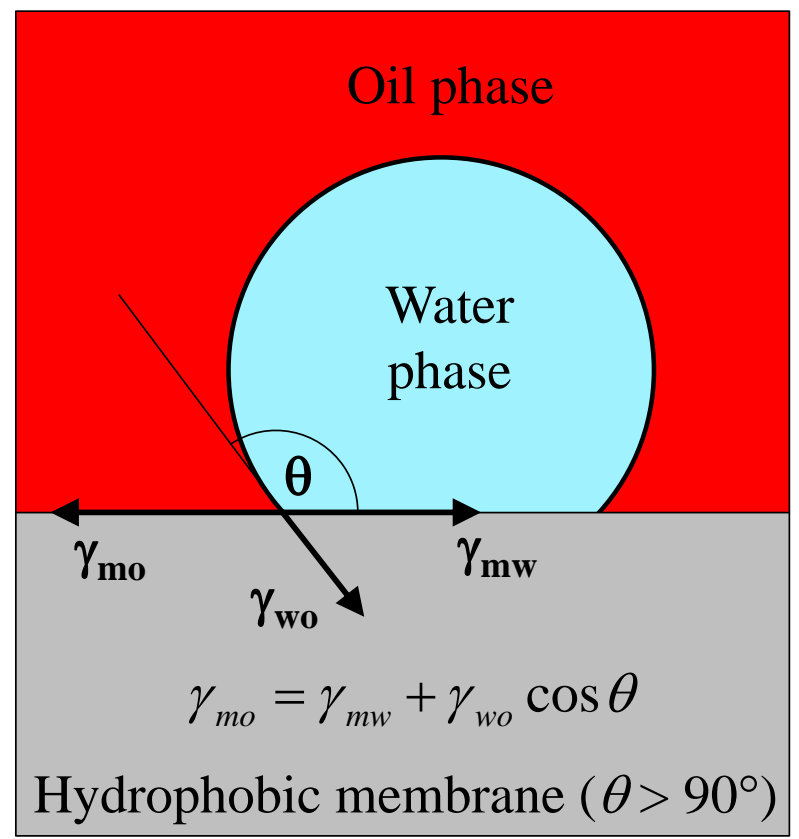

Figure 12 


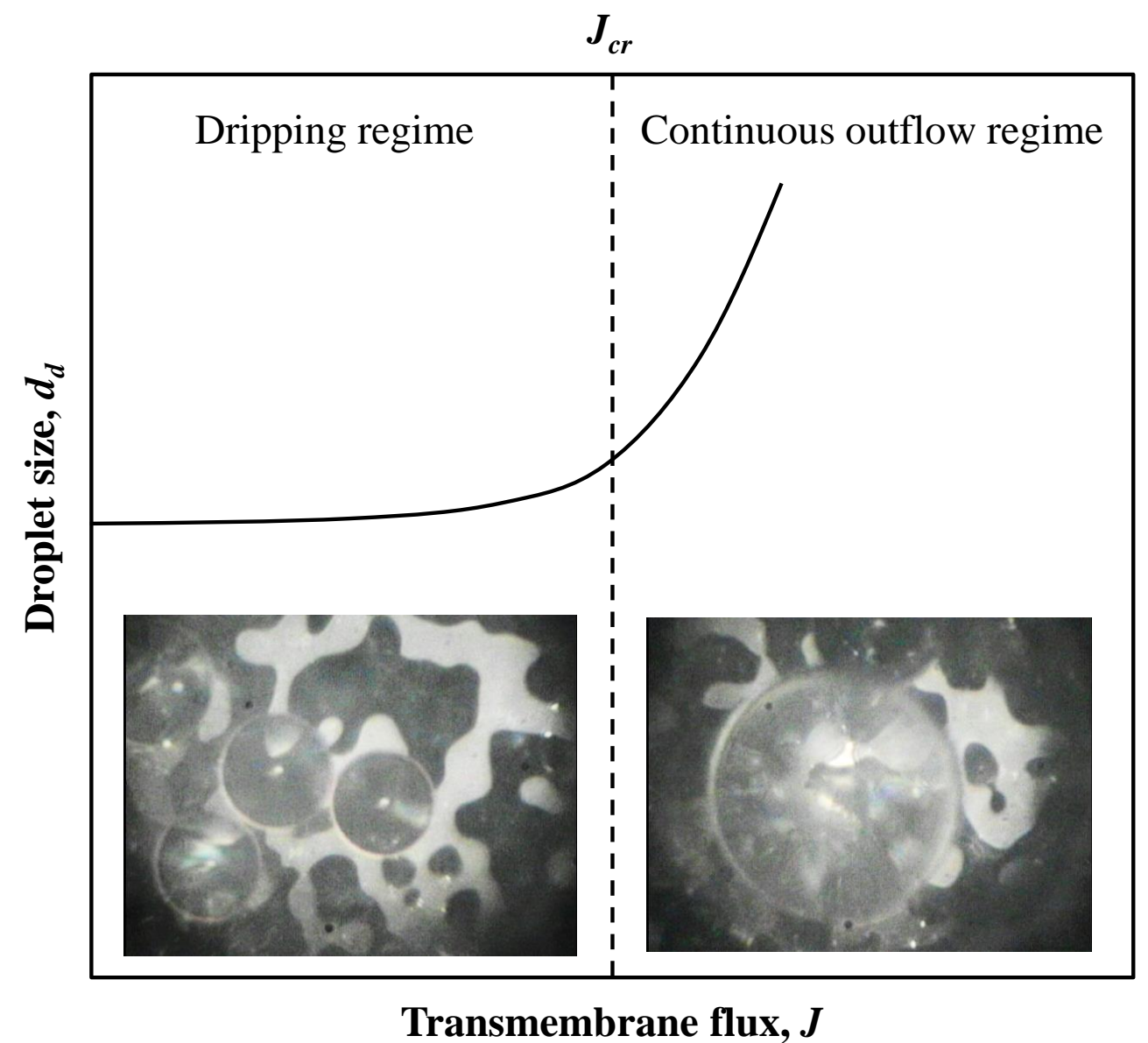

Figure 13 


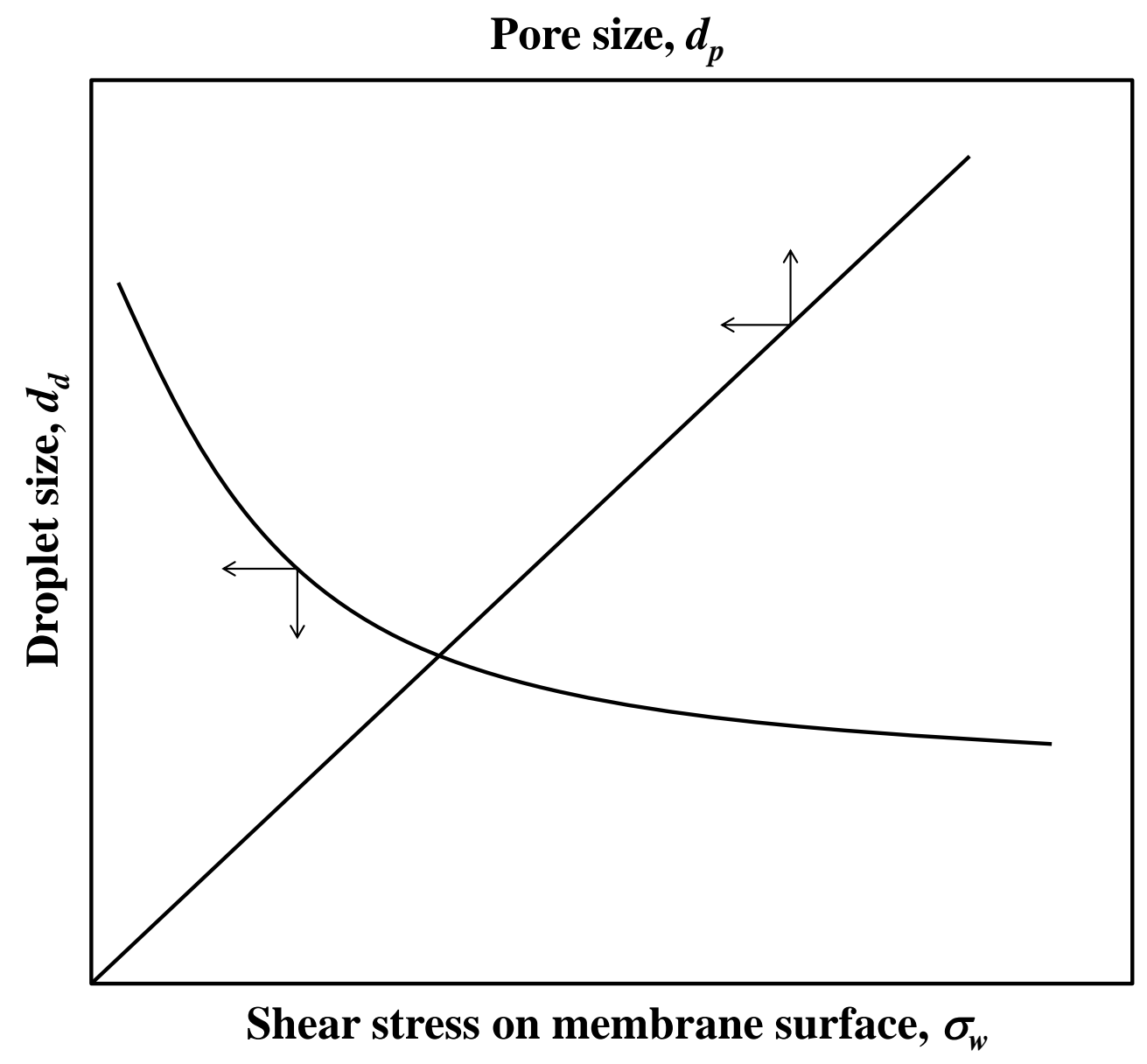

Figure 14 


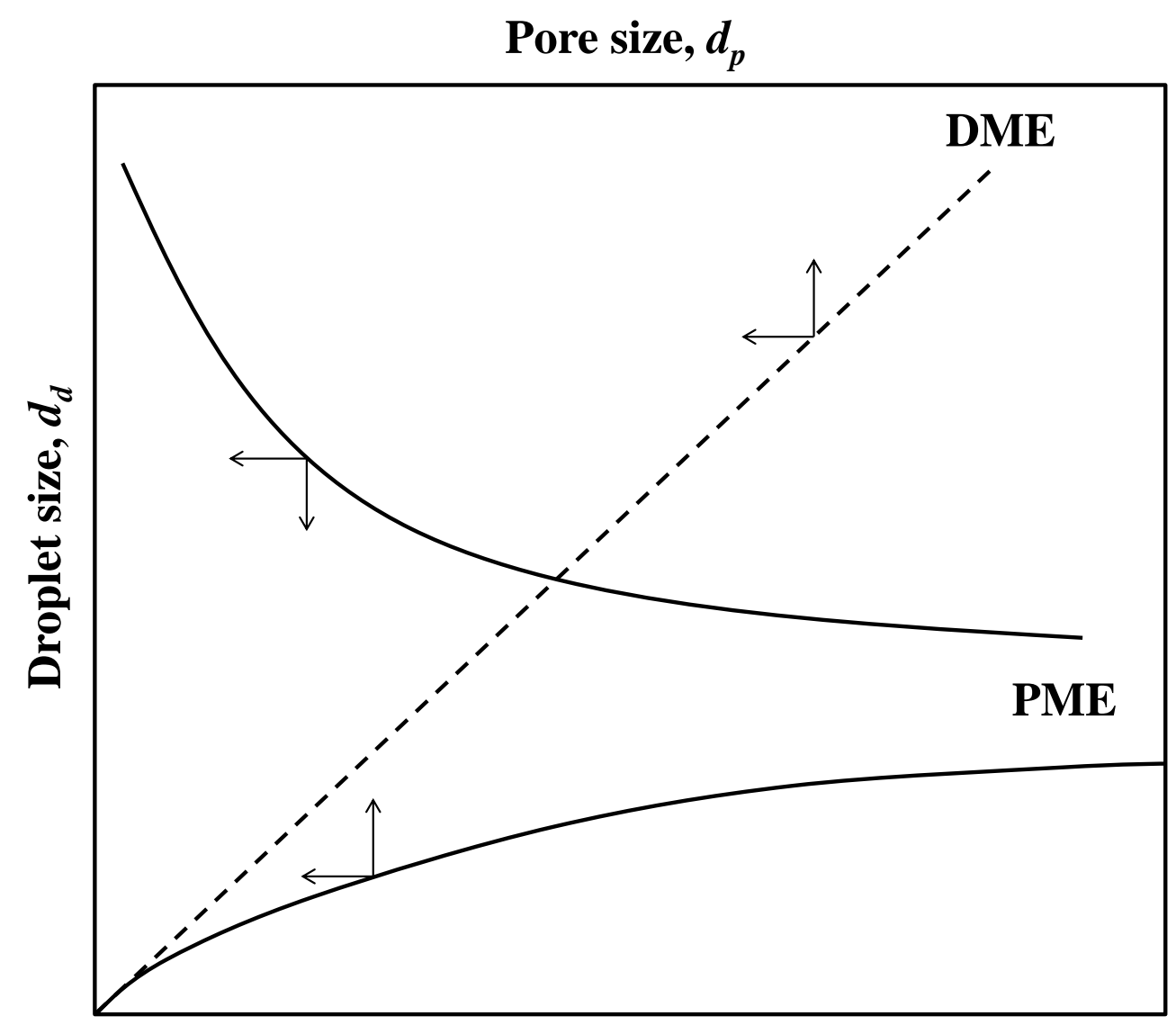

Transmembrane flux, $J$

Figure 15 


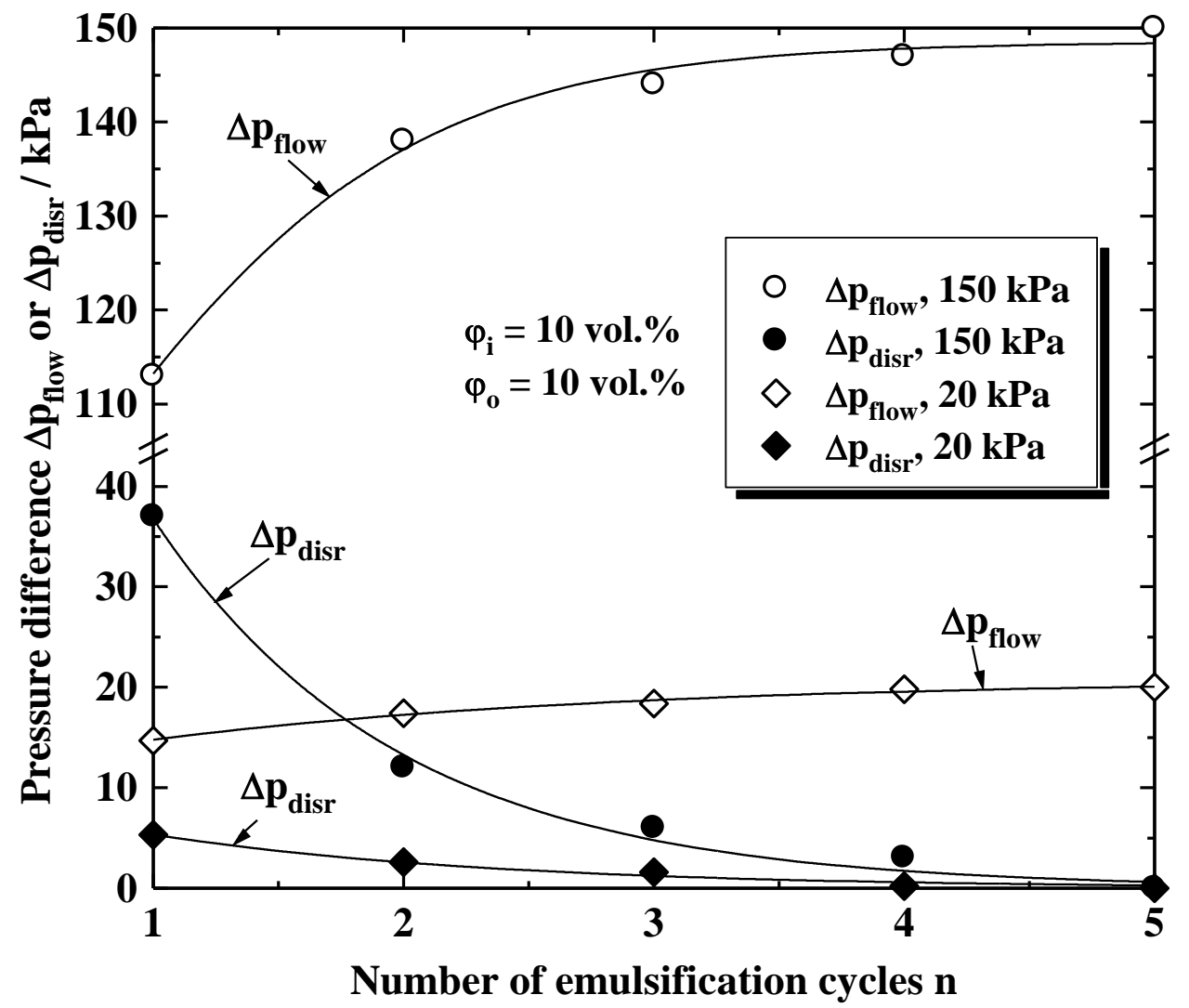

Figure 16 
(a)

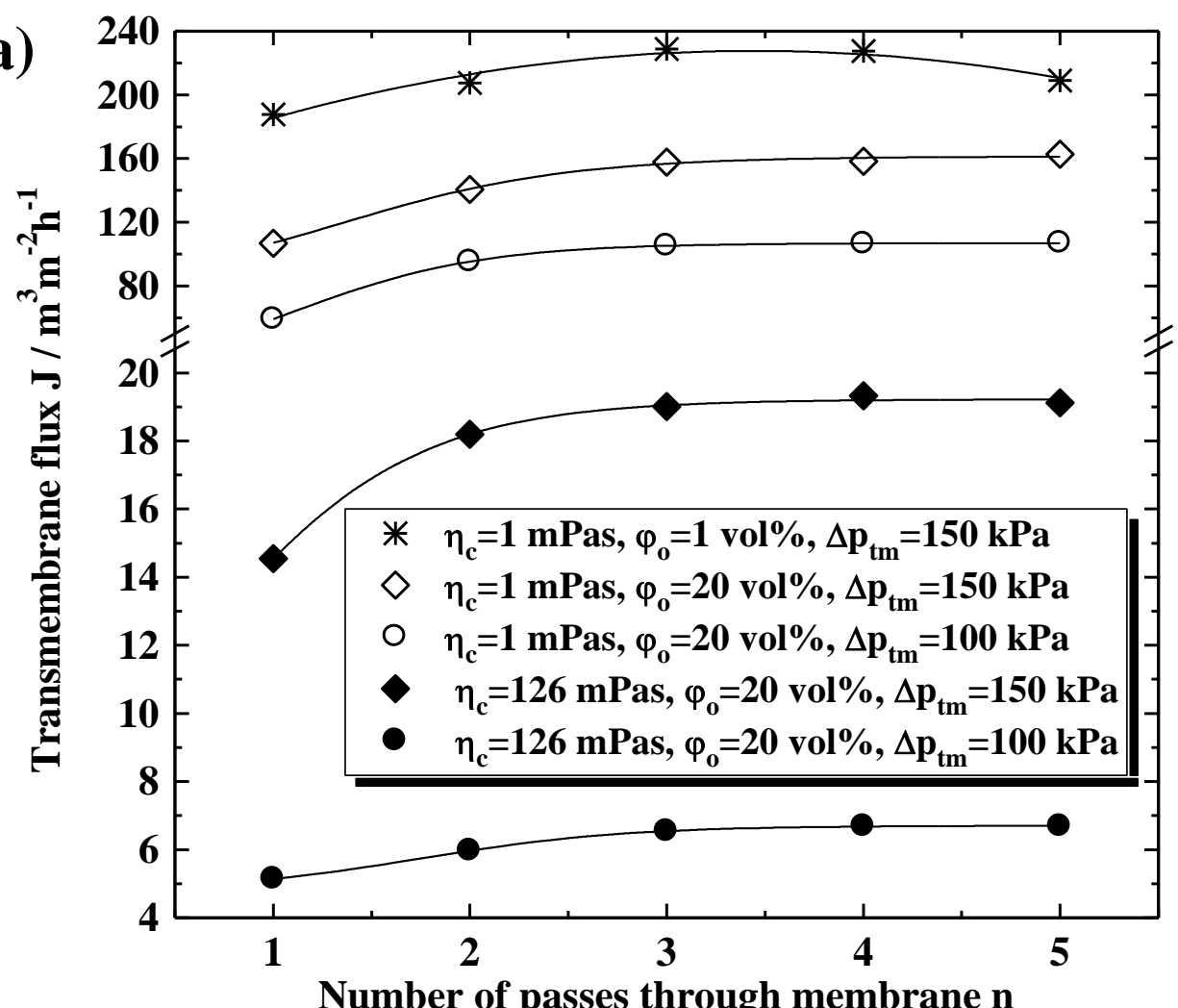

(b)

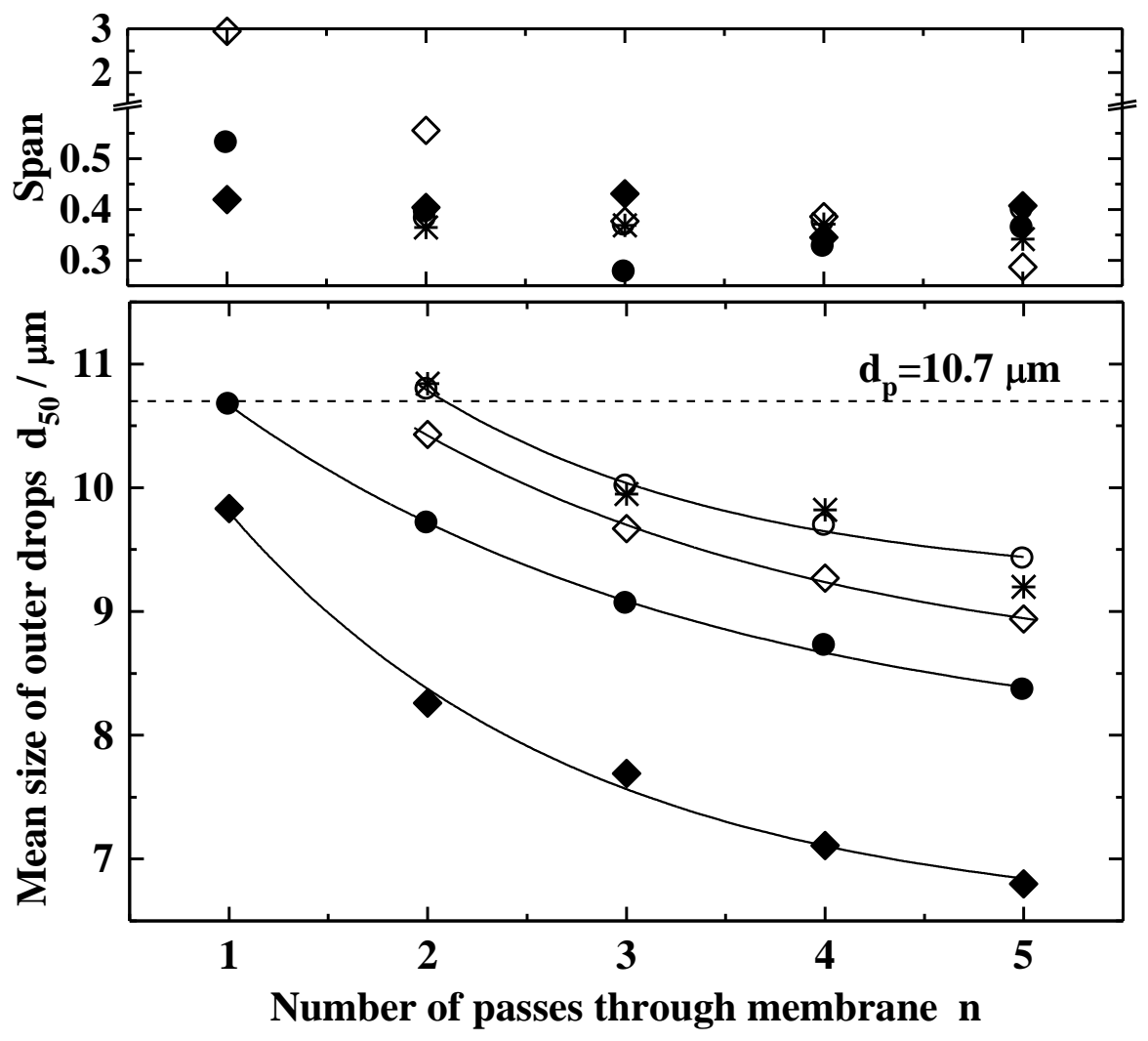

Figure 17 


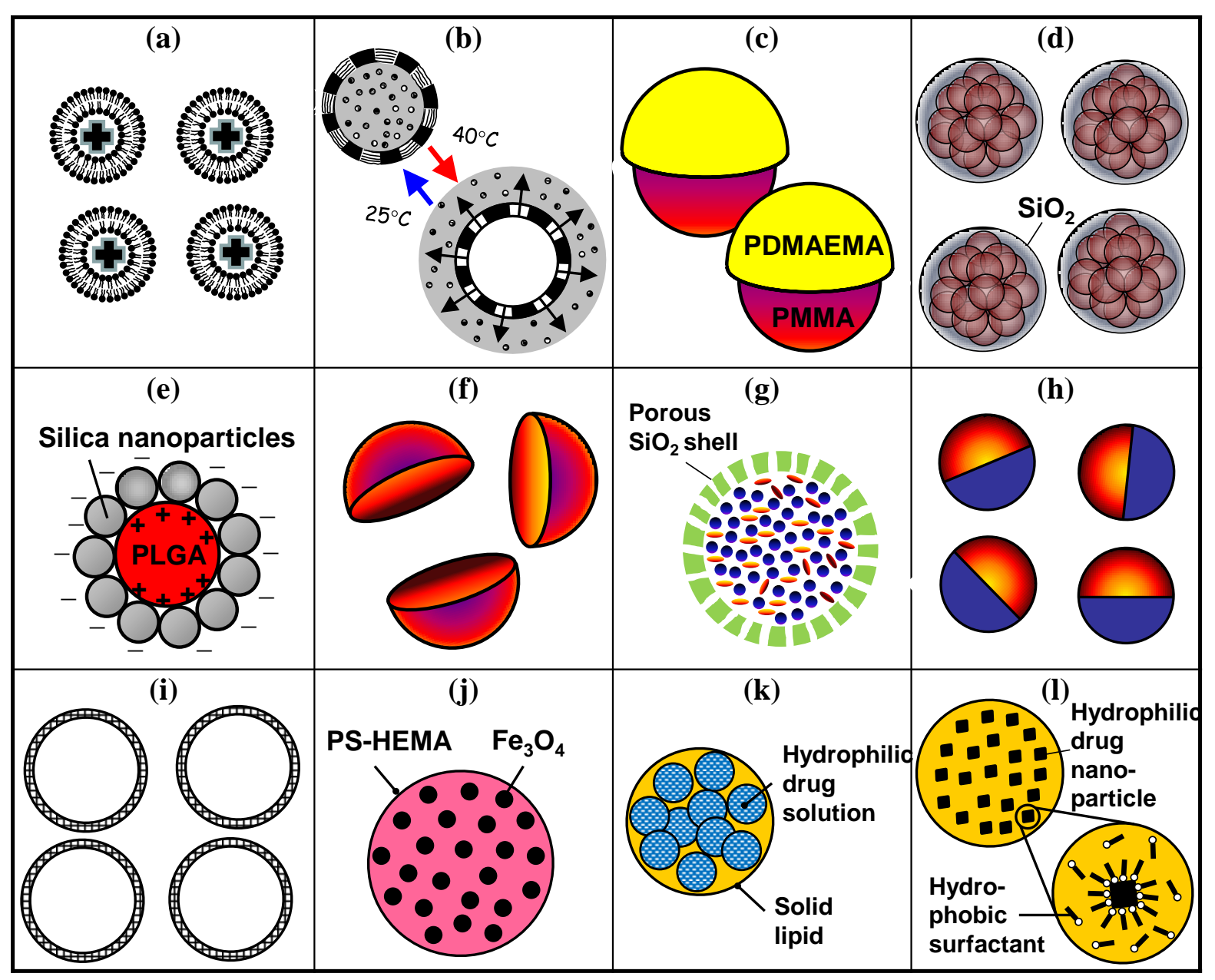

Figure 18 